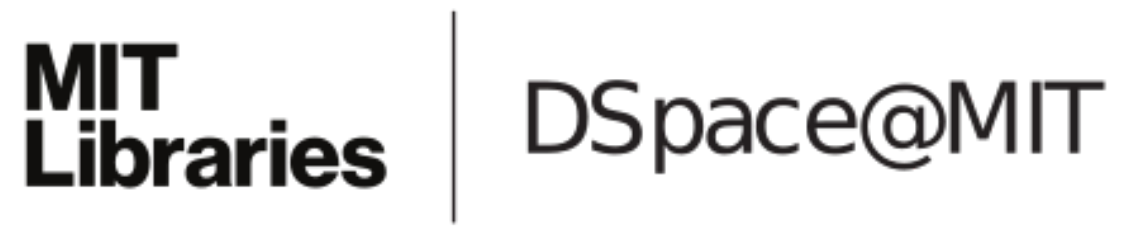

\author{
MIT Open Access Articles
}

\section{Fast Magic-Angle-Spinning 19F Spin Exchange NMR for Determining Nanometer 19F-19F Distances in Proteins and Pharmaceutical Compounds}

The MIT Faculty has made this article openly available. Please share how this access benefits you. Your story matters.

Citation: Roos, Matthias, et al., "Fast Magic-Angle-Spinning 19F Spin Exchange NMR for Determining Nanometer 19F-19F Distances in Proteins and Pharmaceutical Compounds." Journal of Physical Chemistry B 122, 11 (Feb. 2018): p. 2900-11 doi 10.1021/ACS.JPCB.8B00310 (C)2018 Author(s)

As Published: $10.1021 /$ ACS.JPCB.8B00310

Publisher: American Chemical Society (ACS)

Persistent URL: https://hdl.handle.net/1721.1/125915

Version: Author's final manuscript: final author's manuscript post peer review, without publisher's formatting or copy editing

Terms of Use: Article is made available in accordance with the publisher's policy and may be subject to US copyright law. Please refer to the publisher's site for terms of use. 


\title{
Fast Magic-Angle-Spinning ${ }^{19} \mathrm{~F}$ Spin Exchange NMR for Determining Nanometer ${ }^{19}$ F-19F Distances in Proteins and Pharmaceutical Compounds
}

\author{
Matthias Roos, Tuo Wang $\$$, Alexander A. Shcherbakov, and Mei Hong \\ Department of Chemistry, Massachusetts Institute of Technology, 170 Albany Street, Cambridge, \\ MA 02139
}

\begin{abstract}
Internuclear distances measured using NMR provide crucial constraints of three-dimensional structures, but are often restricted to about $5 \AA$ due to the weakness of nuclear-spin dipolar couplings. For studying macromolecular assemblies in biology and materials science, distance constraints beyond $1 \mathrm{~nm}$ will be extremely valuable. Here we present an extensive and quantitative analysis of the feasibility of ${ }^{19} \mathrm{~F}$ spin exchange NMR for precise and robust measurements of interatomic distances to $1.6 \mathrm{~nm}$ at a magnetic field of 14.1 Tesla, under $20-40 \mathrm{kHz}$ magic-angle spinning (MAS). The measured distances are comparable to those achievable from paramagnetic relaxation enhancement, but have higher precision, which is better than $\pm 1 \AA$ for short distances and $\pm 2 \AA$ for long distances. For ${ }^{19} \mathrm{~F}$ spins with the same isotropic chemical shift but different anisotropic chemical shifts, intermediate MAS frequencies of $15-25 \mathrm{kHz}$ without ${ }^{1} \mathrm{H}$ irradiation accelerate spin exchange. For spectrally resolved ${ }^{19} \mathrm{~F}-{ }^{19} \mathrm{~F}$ spin exchange, ${ }^{1} \mathrm{H}-{ }^{19} \mathrm{~F}$ dipolar recoupling significantly speeds up ${ }^{19} \mathrm{~F}-{ }^{19} \mathrm{~F}$ spin exchange. Based on data from five fluorinated synthetic, pharmaceutical and biological compounds, we obtained two general curves for spin exchange between $\mathrm{CF}$ groups and between $\mathrm{CF}_{3}$ and $\mathrm{CF}$ groups. These curves allow ${ }^{19} \mathrm{~F}-{ }^{19} \mathrm{~F}$ distances to be extracted from the measured spin exchange rates after taking into account ${ }^{19} \mathrm{~F}$ chemical shifts. These results demonstrate the robustness of ${ }^{19} \mathrm{~F}$ spin exchange NMR for distance measurements in a wide range of biological and chemical systems.
\end{abstract}

\section{Graphical Abstract}

\footnotetext{
Corresponding author: Mei Hong, meihong@mit.edu. \$ Current address: Department of Chemistry, Louisiana State University, Baton Rouge, LA 70803.

Supporting Information Available:

Additional NMR spectra and table include:

- $\quad$ Method for deriving the optimal MAS frequency for CODEX anisotropy spin exchange.

- Motivation for, and limitations of, the chemical-shift bias correction

- $\quad$ Representative ${ }^{19} \mathrm{~F}$ sideband spectra for extracting the ${ }^{19} \mathrm{~F}$ CSA.

- $\quad{ }^{19}$ F PDSD buildup curves for sitagliptin.

- $\quad$ Comparison of the spin exchange buildup time constants for PDSD and CORD experiments.
}

This material is available free of charge via the Internet at http://pubs.acs.org. 


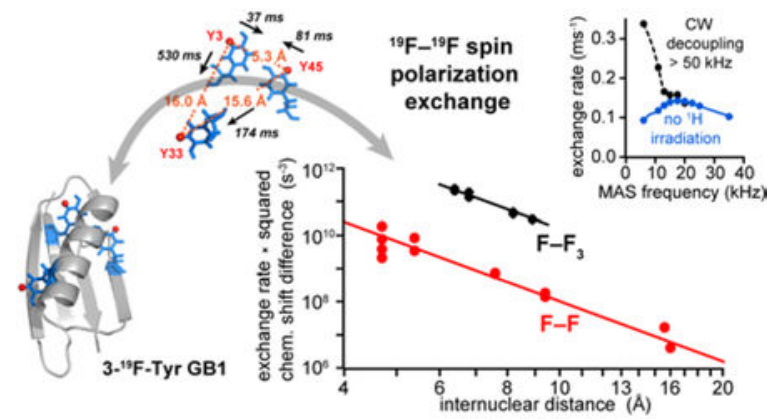

\section{Introduction}

Inter-atomic distances represent the most important constraints in three-dimensional structure determination by NMR. While short-range distances $(<5 \AA)$ can be precisely measured using a variety of NMR experiments, long-range distances between well separated segments in biomolecules are more challenging to measure, but are crucial constraints of the three-dimensional folds of proteins and other macromolecules ${ }^{1}$. For oligomeric systems such as $\alpha$-helical bundles, $\beta$-barrels, and cross- $\beta$ fibrils, intermolecular distances over $1 \mathrm{~nm}$ are invaluable for determining the structures of the intermolecular interfaces.

Magic-angle-spinning (MAS) NMR has been used extensively to measure distances in insoluble and non-crystalline biomolecules and organic compounds ${ }^{2-4}$. The most common solid-state NMR (SSNMR) approach for distance measurements is to detect ${ }^{13} \mathrm{C}-{ }^{13} \mathrm{C}$ cross peaks in $2 \mathrm{D}$ or $3 \mathrm{D}$ correlation spectra as a semi-quantitative indicator of inter-atomic distances ${ }^{5-7}$. These ${ }^{13} \mathrm{C}-{ }^{13} \mathrm{C}$ cross peaks are commonly measured using spin diffusion techniques based on second-order recoupling, such as proton-driven spin diffusion (PDSD) ${ }^{8}$, dipolar-assisted rotational resonance or RF assisted spin diffusion (DARR/RAD) ${ }^{9-10}$, proton-assisted recoupling (PAR $)^{11}$, second-order Hamiltonian among analogous nuclei generated by hetero-nuclear assistance irradiation (SHANGHAI) and its analogs ${ }^{12-14}$, and combined $R 2_{n}^{v}$-driven spin diffusion $(\mathrm{CORD})^{15}$. Although these second-order recoupling techniques have become increasingly more robust with respect to isotropic chemical shift differences and fast MAS in high magnetic fields, the upper limit of measurable ${ }^{13} \mathrm{C}-{ }^{13} \mathrm{C}$ distances is still fundamentally limited by the low ${ }^{13} \mathrm{C}$ gyromagnetic ratio, which weakens the ${ }^{13} \mathrm{C}-{ }^{13} \mathrm{C}$ dipolar coupling, to about $7-8 \AA^{16}$. Further, for uniformly ${ }^{13} \mathrm{C}$-labeled proteins, even independent of dipolar truncation ${ }^{17}$, relayed polarization transfer involving three or more ${ }^{13} \mathrm{C}$ spins remains much more efficient than direct polarization transfer, which makes ${ }^{13} \mathrm{C}-{ }^{13} \mathrm{C}$ cross peaks sensitive to the geometry of the local spin network and less accurately reflecting the long-range ${ }^{13} \mathrm{C}-{ }^{13} \mathrm{C}$ distance of interest. Finally, for organic and pharmaceutical compounds that are not readily amenable to ${ }^{13} \mathrm{C}$ labeling, ${ }^{13} \mathrm{C}-{ }^{13} \mathrm{C}$ distance measurements have very low sensitivity due to the $1.1 \%$ natural abundance of ${ }^{13} \mathrm{C}$, unless sensitivity enhancement techniques such as dynamic nuclear polarization (DNP) are employed ${ }^{18}$.

Compared to homonuclear distances, heteronuclear distances can be measured quantitatively using REDOR ${ }^{19}$ and other recoupling techniques ${ }^{20}$, with ${ }^{13} \mathrm{C}-{ }^{15} \mathrm{~N}$ distance being the most 
commonly measured distances in protein structure determination. However, the ${ }^{15} \mathrm{~N}$ gyromagnetic ratio is even lower than that of ${ }^{13} \mathrm{C}$, so that ${ }^{13} \mathrm{C}-{ }^{15} \mathrm{~N}$ distances cannot be measured beyond $\sim 5 \AA$ A. Paramagnetic relaxation enhancement (PRE) NMR represents a third class of approach that can access much longer distances by making use of unpaired electron spins that enhance nuclear $T_{1}$ or $T_{2}$ relaxation in a distance-dependent manner ${ }^{21}$. Because of the $2-3$ orders of magnitude larger electron gyromagnetic ratio over nuclear gyromagnetic ratios, distances up to $\sim 20 \AA$ can be measured from PRE effects ${ }^{22-26}$. However, paramagnetic dipolar relaxation does not give as precise distances as direct dipolar couplings, and requires either endogenous paramagnetic centers or incorporation of paramagnetic tags at carefully chosen locations that do not perturb protein structures ${ }^{27}$. Therefore, distance measurement for high-resolution biomolecular structure determination by NMR is still largely limited to sub-nanometer distances.

${ }^{19} \mathrm{~F}$ NMR has long been recognized as having several major advantages for structure determination. First, ${ }^{19} \mathrm{~F}$ is absent in naturally occurring biomolecules, thus synthetic and biosynthetic incorporation of fluorine into biomolecules provides site-specific probes of molecular structures without a background. Fluorine incorporation also causes much less structural perturbation than paramagnetic additives or fluorescent labels ${ }^{28-30}$, since fluorine has a van der Waals radius that is similar to that of ${ }^{1} \mathrm{H}$. Second, ${ }^{19} \mathrm{~F}$ spins have large isotropic and anisotropic chemical shifts, thus they are extremely sensitive to the chemical structure and conformational structure of molecules. Third, ${ }^{19} \mathrm{~F}$ is $100 \%$ abundant and has a gyromagnetic ratio that is almost as high $(94 \%)$ as that of ${ }^{1} \mathrm{H}$. Thus, ${ }^{19} \mathrm{~F}$ NMR has extremely high sensitivity. For these reasons, ${ }^{19} \mathrm{~F}$ NMR has become increasingly adopted in biomolecular structure determination, especially for challenging systems such as membranebound G-protein coupled receptors ${ }^{31-33}$. Finally, fluorine is already incorporated in more than $\sim 20 \%$ of pharmaceutical compounds because of its favorable chemical properties ${ }^{30,34}$, which makes ${ }^{19} \mathrm{~F}$ NMR a natural probe of protein-drug and protein-ligand interactions.

One benefit of the high ${ }^{19} \mathrm{~F}$ gyromagnetic ratio is the strong ${ }^{19} \mathrm{~F}-{ }^{19} \mathrm{~F}$ dipolar coupling: for the same distances ${ }^{19} \mathrm{~F}-{ }^{19} \mathrm{~F}$ dipolar couplings are 14 -fold stronger than ${ }^{13} \mathrm{C}-{ }^{13} \mathrm{C}$ dipolar couplings; conversely, for the same dipolar couplings ${ }^{19} \mathrm{~F}-{ }^{19} \mathrm{~F}$ distances are 2.4-fold longer than ${ }^{13} \mathrm{C}-{ }^{13} \mathrm{C}$ distances, suggesting that ${ }^{19} \mathrm{~F}-{ }^{19} \mathrm{~F}$ distances up to $\sim 19 \AA$, as compared to ${ }^{13} \mathrm{C}-$ ${ }^{13} \mathrm{C}$ distances up to $\sim 8 \AA$, may be measurable. Indeed, polarization transfer between fluorine spins with the same isotropic chemical shift but different anisotropic chemical shifts has been exploited using the CODEX technique ${ }^{35}$ to measure intermolecular distances in homooligomeric protein assemblies ${ }^{36-42}$. This ${ }^{19} \mathrm{~F}$ "anisotropy spin exchange" has so far been mainly employed at moderate magnetic fields such as 9.4 Tesla (corresponding to a ${ }^{19} \mathrm{~F}$ Larmor frequency of $376 \mathrm{MHz}$ ), where the ${ }^{19} \mathrm{~F}$ chemical shift anisotropy (CSA) is not very large. Under this condition, low MAS frequencies of $\sim 10 \mathrm{kHz}$ can be employed to avoid slowing down ${ }^{19} \mathrm{~F}^{19} \mathrm{~F}$ spin diffusion. However, low magnetic fields reduce the sensitivity of the experiment and compromise the resolution of chemically distinct ${ }^{19} \mathrm{~F}$ spins. To date, only a small number of studies have explored spectrally resolved ${ }^{19} \mathrm{~F}-{ }^{19} \mathrm{~F}$ distance measurements in small molecules ${ }^{43}$, fluorinated polymers ${ }^{44}$, and inorganic fluorides ${ }^{45-47}$. These studies have been mostly conducted at moderate magnetic fields, focused on distances of $<1 \mathrm{~nm}$, and did not consider the effects of the ${ }^{19} \mathrm{~F}$ chemical shifts on the accuracy of distance extraction. 
Here we present a systematic exploration of the accurate measurement of ${ }^{19} \mathrm{~F}-{ }^{19} \mathrm{~F}$ distances up to $1.6 \mathrm{~nm}$ at a magnetic field of 14.1 Tesla under $20-40 \mathrm{kHz}$ MAS. We demonstrate zero-quantum ${ }^{19} \mathrm{~F}$ spin polarization exchange in organic molecules, pharmaceutical compounds, peptides and proteins that contain both trifluoromethyl groups and aromatic fluorines. We consider both anisotropy spin exchange observed in $1{ }^{19} \mathrm{~F} \mathrm{NMR}$ spectra and spectrally resolved spin exchange in $2 \mathrm{D}{ }^{19} \mathrm{~F}-{ }^{19} \mathrm{~F}$ correlation spectra. For exchange between ${ }^{19} \mathrm{~F}$ spins with the same isotropic chemical shift but different anisotropic shifts, we investigated the optimal ${ }^{1} \mathrm{H}$ irradiation condition and MAS frequency regime, and show that anisotropy spin exchange can be faster under fast MAS than under slow MAS, in contrast to expectation. For spectrally resolved spin exchange, we show that $2 \mathrm{D}{ }^{19} \mathrm{~F}-{ }^{19} \mathrm{~F}$ correlation experiments can yield distances with quantifiable dependence on chemical shifts. We identified two master curves, one for $\mathrm{CF}_{3}-\mathrm{F}$ and the other for $\mathrm{F}-\mathrm{F}$, which relate the polarization transfer rates to ${ }^{19} \mathrm{~F}-{ }^{19} \mathrm{~F}$ distances. These results promise a robust and highsensitivity NMR approach for measuring distance constraints in proteins and pharmaceutical compounds.

\section{Materials and Methods}

\section{Preparation of fluorinated compounds}

Five fluorinated compounds are used in this study (Table 1). ${ }^{5-}{ }^{19} \mathrm{~F}-\mathrm{L}-$ tryptophan (5F-Trp), 7 Chloro-1-(2,4-Difluorophenyl)-6-Fluoro-4-oxo-1,4-Dihydro [1,8] naphthyridine-3carboxylic acid (PNC) and sitagliptin phosphate $\left(\mathrm{C}_{16} \mathrm{H}_{15} \mathrm{~F}_{6} \mathrm{~N}_{5} \mathrm{O} \cdot \mathrm{H}_{3} \mathrm{PO}_{4} \cdot \mathrm{H}_{2} \mathrm{O}\right)$ were purchased from Sigma Aldrich. Formyl-trifluoromethionine- ${ }^{13} \mathrm{C},{ }^{15} \mathrm{~N}$-leucine-para- ${ }^{19} \mathrm{~F}$ phenylalanine (formyl-MLF) was custom-synthesized by Biopeptek Pharmaceuticals (Malvern, PA).

5F-Trp was studied as a dry neat powder, while PNC, sitagliptin and formyl-MLF were diluted with co-solutes at a $1: 5$ or $1: 6$ mass ratio to avoid intermolecular polarization transfer. PNC and unlabeled Trp at $1: 5$ mass ratio were co-dissolved in a $1: 3$ isopropanol : water solution at $60^{\circ} \mathrm{C}$ and sonicated until complete dissolution. Sitagliptin was dissolved in water and mixed with unlabeled Trp at a 1:6 mass ratio, briefly heated up to $80^{\circ} \mathrm{C}$ and sonicated. Formyl-MLF was dissolved in acetic acid and mixed with non-fluorinated formyl$\mathrm{MLF}$ at a $1: 6$ mass ratio at $60^{\circ} \mathrm{C}$, again with sonication. After complete dissolution, each sample was rapidly frozen in liquid nitrogen and lyophilized, giving homogeneous powders that were packed into $1.9 \mathrm{~mm}$ MAS rotors. Freeze-drying was used instead of cocrystallization to avoid self-association and clustering of the fluorinated compounds, and to prevent precipitation of the compound with lower solubility upon increasing solute concentration.

3- ${ }^{19}$ F-Tyr labeled GB1 (3F-Tyr-GB1) was expressed in BL21 (DE3) E. coli cells containing GB1 plasmids that were cultured on ampicillin-containing LB agar. A single colony was used to inoculate $10 \mathrm{ml}$ of $\mathrm{LB}$ for $12-14 \mathrm{hrs}$ at $37^{\circ} \mathrm{C}$. A $5.0 \mathrm{~mL}$ aliquot of the cultured bacteria was transferred to $500 \mathrm{~mL}$ of unlabeled $\left({ }^{12} \mathrm{C},{ }^{14} \mathrm{~N}\right) \mathrm{M} 9$ media $\left(48.1 \mathrm{mM} \mathrm{Na} \mathrm{HPO}_{4}\right.$, $22.0 \mathrm{mM} \mathrm{KH}_{2} \mathrm{PO}_{4}, 8.56 \mathrm{mM} \mathrm{NaCl}, 2.00 \mathrm{mM} \mathrm{MgSO}_{4}, 0.100 \mathrm{mM} \mathrm{CaCl}_{2}, 1.00 \mathrm{~g} / \mathrm{L} \mathrm{NH}_{4} \mathrm{Cl}$, $2.00 \mathrm{~g} / \mathrm{L}$ glucose, $100 \mu \mathrm{g} / \mathrm{mL}$ ampicillin), and was allowed to grow to $\mathrm{OD}_{600}=0.4 .50 \mathrm{mg}$ of unlabeled L-phenylalanine, L-tryptophan, and 3-fluoro-L-tyrosine were dissolved in $5 \mathrm{ml}$ of 
M9 media at $50{ }^{\circ} \mathrm{C}$. The cells were then spun down at $7000 \mathrm{rpm}$ and $25{ }^{\circ} \mathrm{C}$ for 10 minutes. The pellet was resuspended in $500 \mathrm{~mL}$ of $\mathrm{M} 9$ media containing ${ }^{15} \mathrm{NH}_{4} \mathrm{Cl}$ and ${ }^{13} \mathrm{C}$-glucose. Glyphosate was added to a final concentration of $1 \mathrm{~g} / \mathrm{L}$ after 30 minutes and the temperature was changed to $28{ }^{\circ} \mathrm{C}$, then unlabeled L-phenylalanine and L-tryptophan, and 3-fluoro-Ltyrosine solutions were added to the culture. When $\mathrm{OD}_{600}$ reached 0.6, isopropyl $\beta$-Dthiogalactoside (IPTG) was added to a concentration of $0.5 \mathrm{mM}$ to induce protein expression for $5-6 \mathrm{hrs}$. The cells were spun down at $7000 \mathrm{rpm}$ and $4{ }^{\circ} \mathrm{C}$ for 15 minutes and the bacterial pellet was resuspended in $50 \mathrm{~mL}$ of lysis buffer $\left(200 \mathrm{mM} \mathrm{NaCl}, 50 \mathrm{mM} \mathrm{KH}{ }_{2} \mathrm{PO}_{4} /\right.$ $\mathrm{K}_{2} \mathrm{HPO}_{4}, \mathrm{pH}$ 7). The suspension was heated in a water bath at $80^{\circ} \mathrm{C}$ for $5 \mathrm{~min}$ and then chilled on ice for $15 \mathrm{~min}$. The mixture was centrifuged at $16,000 \mathrm{~g}$ and $4{ }^{\circ} \mathrm{C}$ for 1 hour to pellet insoluble cell matter. The supernatant was concentrated to $\sim 10 \mathrm{~mL}$ using Amicon Ultra-15 3,000 Dalton molecular weight cut-off (MWCO) centrifugal concentrators (Millipore). The protein was purified by size-exclusion chromatography using a HiLoad 26/60 Superdex 75 prep grade column (GE) using a $50 \mathrm{mM} \mathrm{KH_{2 }} \mathrm{PO}_{4} / \mathrm{K}_{2} \mathrm{HPO}_{4}, 100 \mathrm{mM}$ $\mathrm{NaCl}$ buffer at $\mathrm{pH}$ 7.0. The yield of the purified protein was determined by UV-VIS at 280 $\mathrm{nm}$ to be $50 \mathrm{mg}$ from $500 \mathrm{~mL}$ of culture. The purified protein solution was dialyzed against $4 \mathrm{~L}$ of $50 \mathrm{mM} \mathrm{KH}_{2} \mathrm{PO}_{4} / \mathrm{K}_{2} \mathrm{HPO}_{4}$ buffer at $\mathrm{pH} 5.5$ to remove $\mathrm{NaCl}$. The dialysis buffer was changed twice a day for four days. Microcrystalline protein was obtained by mixing $1 \mathrm{~mL}$ of $30 \mathrm{mg} / \mathrm{mL}$ GB 1 solution with three $1 \mathrm{~mL}$ aliquots of crystalizing solution containing 2methyl-2,4-pentanediol (MPD) and isopropanol (IPA) at a volume ratio of $2: 1$. The microcrystalline protein was packed into a $1.9 \mathrm{~mm}$ MAS rotor containing two silicone antidehydration spacers between the end caps and the rotor body. About $12 \mathrm{mg}$ of GB1 microcrystals and organic solution were packed into the rotor. The fluoro-tyrosine incorporation level was determined to be $95 \%$ using ESI and MALDI-TOF mass spectrometry.

\section{Solid-state NMR experiments}

Solid-state NMR experiments were conducted on a Bruker Avance III HD spectrometer operating at a magnetic field of 14.1 Tesla and a ${ }^{19} \mathrm{~F}$ Larmor frequency of $564.66 \mathrm{MHz}$. A $1.9 \mathrm{~mm}$ MAS HFX probe with a maximum MAS frequency of $42 \mathrm{kHz}$ was used. ${ }^{19} \mathrm{~F}$ chemical shifts were referenced to the $-122.1 \mathrm{ppm}$ chemical shift of 5F-Trp on the $\mathrm{CF}_{3} \mathrm{Cl}$ $\mathrm{scale}^{37} .2 \mathrm{D}{ }^{19} \mathrm{~F}-{ }^{19} \mathrm{~F}$ correlation spectra were measured under $25 \mathrm{kHz}$ MAS. CODEX experiments on 5F-Trp were conducted from $6 \mathrm{kHz}$ to $35 \mathrm{kHz}$ MAS to investigate the dependence of spin exchange on MAS frequency. Sample temperature was maintained at $\sim 300 \mathrm{~K}$ by adjusting the temperature set point such that the MAS frictional heating effects are compensated ${ }^{48}$.

For 5F-Trp, PNC and GB1, ${ }^{1} \mathrm{H}-{ }^{19} \mathrm{~F}$ cross polarization $(\mathrm{CP})$ was used to avoid long recycle delays due to the long ${ }^{19} \mathrm{~F} T_{1}$ relaxation times. For the four samples with resolved ${ }^{19} \mathrm{~F}$ isotropic chemical shifts, $2 \mathrm{D}^{19} \mathrm{~F}-{ }^{19} \mathrm{~F}$ exchange spectra were measured using the $\mathrm{CORD}{ }^{1} \mathrm{H}$ irradiation scheme ${ }^{49}$ during the mixing period. For sitagliptin, additional 2D spectra without ${ }^{1} \mathrm{H}$ irradiation during mixing, i.e. PDSD, were measured to compare the efficiency of spin exchange with and without ${ }^{19} \mathrm{~F}-{ }^{1} \mathrm{H}$ dipolar recoupling. The ${ }^{1} \mathrm{H}$ rf field strengths for CORD and DARR irradiation were calibrated independently to ensure correct adjustment and comparability between different experiments. 
For 5F-Trp, polarization transfer between magnetically inequivalent spins was measured using the CODEX experiment in the absence of molecular motion ${ }^{35,50}$. CODEX decays were quantified by normalizing the intensity of the exchange spectrum, $S\left(t_{\text {mix }}\right)$, to the intensity of the control spectrum, $S_{0}$. To maintain the same $T_{1}$ relaxation effects between $S$ and $S_{0}$ experiments, a second mixing period serving as a longitudinal relaxation delay of duration $t_{\mathrm{z}}$ was added, where $t_{\mathrm{z}}+t_{\text {mix }}$ is the same between the $S$ and $S_{0}$ experiments. ${ }^{19} \mathrm{~F}$ radiofrequency (rf) field strengths for $90^{\circ}$ and $180^{\circ}$ pulses were calibrated to a nutation frequency of $71.4 \mathrm{kHz}$. The ${ }^{19} \mathrm{~F} 180^{\circ}$ pulses were optimized by maximizing the intensity of the refocused echo signal, which minimizes pulse imperfections during the CSA recoupling periods. The CSA recoupling duration, $N \tau_{r}$, where $\tau_{\mathrm{r}}$ is the rotor period, was chosen based on the ${ }^{19} \mathrm{~F} \mathrm{CSA}, \Delta \delta$, which is $29.3 \mathrm{kHz}$ for $5 \mathrm{~F}-\mathrm{Trp}$ at 14.1 Tesla, such that $N \tau_{r} \cdot \Delta \delta=10-$ 13.

\section{Simulations of ${ }^{19} \mathrm{~F}$ anisotropy spin exchange}

The measured spin diffusion rate $k_{\mathrm{SD}}$ for $5 \mathrm{~F}-\mathrm{Trp}$ in the absence of ${ }^{1} \mathrm{H}$ irradiation (Fig. 3a, b) was simulated using the SPINEVOLUTION program ${ }^{51}$. We considered the three closest ${ }^{19} \mathrm{~F}$ spins from three molecules (Fig. 1a), together with their nine closest ${ }^{1} \mathrm{H}$ spins, giving a total of 12 spins in the simulation. Only one of the three spins $\left(\mathrm{F}_{1}\right)$ was given initial $z$-polarization to initiate detectable spin diffusion, while the z-magnetization $I_{\mathrm{z}}$ of its two closest neighbors $\left({ }^{19} \mathrm{~F}_{2},{ }^{19} \mathrm{~F}_{3}\right)$ was monitored as a function of mixing time. Due to symmetry, detecting $\left\langle I_{\mathrm{z}, 2}(t)+I_{\mathrm{z}, 3}(t)\right\rangle / 2$ is equivalent to detecting only $\left\langle I_{\mathrm{z}, 2}(t)\right\rangle$ or only $\left\langle I_{\mathrm{z}, 3}(t)\right\rangle$, since $\left\langle I_{\mathrm{z}, 2}(t)\right\rangle=\left\langle I_{\mathrm{z}, 3}(t)\right\rangle$ after powder averaging. We used 168 crystal orientations created using the REPULSION scheme for powder averaging ${ }^{52}$. Only polarization transfer between ${ }^{19} \mathrm{~F}$ spins of different CSA tensor orientations results in CODEX signal decays. However, the presence of a third ${ }^{19} \mathrm{~F}$ spin $\left({ }^{19} \mathrm{~F}_{3}\right.$, with the same tensor orientation as $\left.{ }^{19} \mathrm{~F}_{2}\right)$ facilitates polarization transfer and affects the MAS dependence of spin exchange ${ }^{53}$. The polarization build-up $\left\langle I_{z, 2}(t)\right\rangle$ is independent of the actual starting configuration and detection scheme, and can be approximated by $I_{\mathrm{z}}(t) \approx W t^{2}$, where $W$ is the polarization transfer rate per unit time and is proportional to the spin diffusion rate $k_{\mathrm{SD}}$ with a proportionality constant that is shared among all simulations ${ }^{53} \cdot{ }^{1} \mathrm{H}-{ }^{19} \mathrm{~F}$ and ${ }^{1} \mathrm{H}-{ }^{1} \mathrm{H}$ dipolar coupling strengths were varied from zero to the rigid limit in the simulations to investigate the impact of ${ }^{1} \mathrm{H}$ dipolar couplings on the optimal MAS frequency under which spin diffusion is most efficient. For each dipolar scaling factor, the spin diffusion build-up curve was simulated as a function of MAS frequency, with the MAS frequency yielding the fastest buildup being identified in Fig. 3b. The best-fit simulation for the ${ }^{1} \mathrm{H}$-undecoupled spin exchange rates in Fig. 3a used a ${ }^{1} \mathrm{H}$ dipolar scaling factor of $1 / 3$ in the simulations, which approximates the fact that the actual (average) ${ }^{1} \mathrm{H}$ couplings to the ${ }^{19} \mathrm{~F}$ spins are smaller than the couplings from the three closest protons to each ${ }^{19} \mathrm{~F}$ used in the simulation. The value of $1 / 3$ was determined by interpolating the impact of the ${ }^{1} \mathrm{H}_{-}{ }^{19} \mathrm{~F}$ and ${ }^{1} \mathrm{H}-{ }^{1} \mathrm{H}$ dipolar coupling strength based on simulations with and without the impact of protons, assuming a linear relationship between the ${ }^{1} \mathrm{H}$ dipolar coupling strength and the MAS frequency under which PDSD is the fastest. Additional simulations with a ${ }^{1} \mathrm{H}$ dipolar rescaling factor of $2 / 3$ indicates that this assumption is justified (Fig. 3b). In addition, effects of the ${ }^{19} \mathrm{~F}$ CSA tensor orientation on ${ }^{19} \mathrm{~F}-{ }^{19} \mathrm{~F}$ 
polarization transfer (Fig. 3c) were simulated using the SIMPSON program ${ }^{54}$, considering only two ${ }^{19} \mathrm{~F}$ spins and no ${ }^{1} \mathrm{H}$.

\section{Results and Discussion}

\section{Spin exchange between chemically equivalent ${ }^{19} \mathrm{~F}$ spins}

We first investigated the optimal conditions for efficient CODEX anisotropy spin exchange at a magnetic field of 14.1 Tesla, using 5F-Trp as the model compound. 5F-Trp has two inequivalent molecules in the asymmetric unit cell ${ }^{37}$, with a ${ }^{19} \mathrm{~F}-{ }^{19} \mathrm{~F}$ distance of $4.6 \AA$ and a relative orientation of $90^{\circ}$ between the two C5-F5 bonds (Fig. 1a). Spinning sideband spectra at 6,11 , and $15 \mathrm{kHz}$ MAS (Fig. 1b) indicate that the chemical shift tensor has an anisotropy $\Delta \delta=\delta_{\mathrm{zz}}-\delta_{\text {iso }}$ of $53.7 \pm 0.8 \mathrm{ppm}$ and an asymmetry parameter of $\eta=0.04 \pm 0.08$, in agreement with literature ${ }^{37,55}$. We measured the 5F-Trp CODEX intensities as a function of MAS frequency (6 to $35 \mathrm{kHz}$ ) and ${ }^{1} \mathrm{H}$ irradiation field strength, $\nu_{1 \mathrm{H}}(0$ to $60 \mathrm{kHz})$.

In the absence of motion, the CODEX experiment probes dipolar polarization transfer between spins with distinct instantaneous chemical shifts ${ }^{35-36,56}$. Spin exchange among $m$ magnetically inequivalent spins reduces the $T_{1}$-compensated echo intensity $S / S_{0}$ to an equilibrium value of $1 / m$ according to

$$
\frac{S\left(t_{\text {mix }}\right)}{S_{0}}=\left(1-\frac{1}{m}\right) e^{-k} \operatorname{SD}^{t} \text { mix }+\frac{1}{m},
$$

where the exponential decay rate, $k_{\mathrm{SD}}$, depends on the distance-dependent dipolar coupling $\omega$ as 37,57

$$
k_{S D} \approx 0.5 \pi \omega^{2} F(0)
$$

Here, $F(0)$ is the overlap integral between the normalized zero-quantum lineshapes $f_{\mathrm{i}}\left(\omega-\omega_{\mathrm{i}}\right)$ of the two spins, and $\omega_{\mathrm{i}}$ is the center of each peak,

$$
F(0)=\int_{-\infty}^{+\infty} f_{\mathrm{i}}\left(\omega-\omega_{\mathrm{i}}\right) f_{\mathrm{j}}\left(\omega-\omega_{\mathrm{j}}\right) \mathrm{d} \omega .
$$

The value of $F(0)$ is affected by ${ }^{19} \mathrm{~F}-{ }^{1} \mathrm{H}$ and ${ }^{1} \mathrm{H}-{ }^{1} \mathrm{H}$ dipolar couplings, which impact the zero-quantum lineshapes. Under MAS, ${ }^{19} \mathrm{~F}-{ }^{1} \mathrm{H}$ dipolar couplings are largely averaged out, but can be reintroduced by ${ }^{1} \mathrm{H}$ continuous-wave $(\mathrm{CW})$ irradiation at the $v_{1}=v_{\mathrm{R}}(n=1)$ or $v_{1}$ $=2 v_{\mathrm{R}}(n=2) \mathrm{DARR}$ condition ${ }^{9,58}$.

Fig. 2a shows CODEX decays of 5F-Trp at $25 \mathrm{kHz}$ MAS for different ${ }^{1} \mathrm{H}$ irradiation field strengths. The equilibrium $\mathrm{S} / \mathrm{S}_{0}$ value is, for different MAS rates, between 0.49 and 0.54 , which is consistent with the unit cell structure. At the DARR conditions of $\nu^{1}{ }_{\mathrm{H}}=25$ and 50 $\mathrm{kHz}$, the CODEX echo intensities decay more slowly compared to other $v_{1 \mathrm{H}}$ values, 
indicating that ${ }^{19} \mathrm{~F}-{ }^{1} \mathrm{H}$ dipolar recoupling slows down rather than speeds up spin exchange. Fig. $2 \mathrm{~b}$ plots the exchange rates $k_{\mathrm{SD}}$ as a function of $\nu_{1 \mathrm{H}}$ for different MAS frequencies. At all MAS frequencies, ${ }^{19} \mathrm{~F}$ spin exchange is slower under the DARR conditions than without ${ }^{1} \mathrm{H}$ irradiation (i.e. PDSD), with differences as much as 5 -fold. This can be understood because ${ }^{1} \mathrm{H}-{ }^{19} \mathrm{~F}$ dipolar couplings experienced by the two ${ }^{19} \mathrm{~F}$ spins differ, thus DARR recoupling reduces the overlap integral for these spins at the same $\omega_{\mathrm{i}}$ or isotropic shift $^{53,59-60}$.

Fig. 3a summarizes the observed joint dependence of $k_{\mathrm{SD}}$ on the MAS frequency and $v_{1 \mathrm{H}}$. In addition to the slow exchange rates under the DARR condition, we observed interesting differences between spin exchange rates under strong ${ }^{1} \mathrm{H}$ decoupling and no ${ }^{1} \mathrm{H}$ decoupling. At slow MAS rates of less than $10 \mathrm{kHz},{ }^{1} \mathrm{H}$ decoupling results in the fastest ${ }^{19} \mathrm{~F}$ spin exchange. For example, at $6 \mathrm{kHz}$ MAS, the polarization transfer rate is 3.5-fold faster with ${ }^{1} \mathrm{H} \mathrm{CW}$ decoupling than without decoupling. As the MAS frequency increases to $15-20$ $\mathrm{kHz}$, which is $2-3$ times the ${ }^{19} \mathrm{~F}-{ }^{1} \mathrm{H}$ dipolar coupling of $8.1 \mathrm{kHz}$ for a $2.4 \AA^{19} \mathrm{~F}-{ }^{1} \mathrm{H}$ distance, spin diffusion rates are similar with and without ${ }^{1} \mathrm{H}$ decoupling. At even faster MAS, ${ }^{1} \mathrm{H}$ decoupling slows down polarization transfer, probably because the decoupling fields of $50-60 \mathrm{kHz}$ approach the $n=2$ DARR condition. In this regime, undecoupled ${ }^{19} \mathrm{~F}$ PDSD spin exchange is the most efficient. In the MAS range of $6-35 \mathrm{kHz},{ }^{1} \mathrm{H}$-undecoupled ${ }^{19} \mathrm{~F}$ spin exchange exhibits the highest exchange rates at MAS frequencies of $15-25 \mathrm{kHz}$, with a maximum at $17.5 \mathrm{kHz}$ MAS.

The existence of an optimal MAS frequency for ${ }^{1} \mathrm{H}$-undecoupled ${ }^{19} \mathrm{~F}$ anisotropy spin exchange can be understood as a compromise between MAS-induced transient level crossings that speed up spin exchange and reduction of ${ }^{19} \mathrm{~F}-{ }^{19} \mathrm{~F}$ dipolar coupling by MAS. We can estimate this optimal frequency using the theory of rotor-driven polarization transfer ${ }^{61}$, by considering the frequency required to match the average instantaneous chemical shift difference between the two ${ }^{19} \mathrm{~F}$ spins (Supporting Information):

$$
\nu_{\mathrm{r}, \mathrm{opt}} \cong|\Delta \delta \cdot \sin \Delta \theta| \frac{\sqrt{\left(18+\eta^{2}\right)(15+\cos (2 \Delta \theta))}}{8 \sqrt{15}} \approx \frac{|\Delta \delta \cdot \sin \Delta \theta|}{2}
$$

where $\Delta \delta$ is the chemical shift anisotropy parameter in the unit of Hertz and $\Delta \theta$ is the angle between the largest chemical shift principal axis of the two ${ }^{19} \mathrm{~F}$ tensors. For 5F-Trp (Table 1), $\Delta \theta=90^{\circ}$, thus Eq. (4) predicts a $\nu_{\mathrm{r}, \mathrm{opt}}$ of $15.5 \mathrm{kHz}$, which is in reasonable agreement with the measured optimal MAS frequency of $17.5 \mathrm{kHz}$ (Fig. 3a). SPINEVOLUTION simulations (solid line in Fig. 3a) using 33\% scaled ${ }^{1} \mathrm{H}-{ }^{19} \mathrm{~F}$ and ${ }^{1} \mathrm{H}-{ }^{1} \mathrm{H}$ dipolar couplings resulted in excellent agreement with the experimentally measured $k_{\mathrm{SD}}$ values as a function of MAS frequency. The scaling of ${ }^{19} \mathrm{~F}-{ }^{1} \mathrm{H}$ dipolar couplings is necessary because only the closest ${ }^{1} \mathrm{H}$ spins were used in the SPINEVOLUTION simulation while the average ${ }^{1} \mathrm{H}-{ }^{19} \mathrm{~F}$ dipolar coupling is weaker. Increasing ${ }^{19} \mathrm{~F}-{ }^{1} \mathrm{H}$ and ${ }^{1} \mathrm{H}-{ }^{1} \mathrm{H}$ dipolar coupling shifts the optimal MAS frequency to larger values, as seen in Fig. $3 b$.

Fig. 3c compares the $\Delta \theta$ dependence of the optimal MAS frequency predicted from Eq. (4) and the simulated optimal MAS frequency using a simplified two-spin simulation. Good 
agreement is seen between the two. The optimal MAS frequency reaches a maximum when the two main principal axes of the CSA tensors are perpendicular to each other, consistent with Eq. (4).

We can express the dependence of ${ }^{19} \mathrm{~F}$ spin diffusion rates on ${ }^{1} \mathrm{H}$ irradiation in terms of an effective ${ }^{19} \mathrm{~F}$ overlap integral, $F_{\text {eff }}(0)$, which can be estimated as the ratio between the measured $k_{\mathrm{SD}}$ and the effective dipolar coupling, $\omega_{\text {eff }}=\left(\sum \omega_{\mathrm{i}}^{2}\right)^{1 / 2}$, as $F_{\text {eff }}(0) \approx k_{S D} / 0.5 \pi \omega_{\text {eff }}^{2}$. For $5 \mathrm{~F}-\mathrm{Trp}, \omega_{\text {eff }}$ is $2 \pi \cdot 2315 \mathrm{~Hz}$ based on previously reported values ${ }^{37}$. The resulting $F_{\text {eff }}(0)$ values for $5 \mathrm{~F}-\mathrm{Trp}$ from 6 to $35 \mathrm{kHz}$ MAS under no ${ }^{1} \mathrm{H}$ irradiation, ${ }^{1} \mathrm{H}$ DARR irradiation, and ${ }^{1} \mathrm{H} \mathrm{CW}$ decoupling, are shown in Table 2 . The values of the effective overlap integral show a moderate dependence on the MAS frequency, and are lower than the value of $37 \mu \mathrm{s}$ measured under $8 \mathrm{kHz}$ MAS at 9.4 Tesla, which can be attributed to the higher magnetic field and larger chemical shift in the current study.

\section{${ }^{19} \mathrm{~F}$ spin exchange between spins with distinct isotropic chemical shifts}

We next turned to ${ }^{19} \mathrm{~F}$ spin exchange between chemically distinct spins for measuring distances in multi-fluorinated proteins and pharmaceutical compounds. It is well known that ${ }^{13} \mathrm{C}$ zero-quantum spin exchange is facilitated by ${ }^{1} \mathrm{H}$ irradiation at a field strength that matches the MAS frequency. Under this DARR or CORD condition, the recoupled ${ }^{1} \mathrm{H}-{ }^{13} \mathrm{C}$ dipolar interaction speeds up ${ }^{13} \mathrm{C}$ spin diffusion. For ${ }^{19} \mathrm{~F}$ spins, isotropic chemical shift differences can be as large as $100 \mathrm{ppm}$, which should make DARR or CORD spin diffusion very beneficial. However, these large chemical shift differences can exceed ${ }^{19} \mathrm{~F}-{ }^{1} \mathrm{H}$ and ${ }^{1} \mathrm{H}-$ ${ }^{1} \mathrm{H}$ dipolar couplings, which may weaken the effect of ${ }^{1} \mathrm{H}-{ }^{19} \mathrm{~F}$ recoupling on spin diffusion. The large ${ }^{19} \mathrm{~F}$ CSA may further complicate polarization transfer by reducing or enhancing the chemical shift difference between the two spins. Thus, accounting for ${ }^{19} \mathrm{~F}$ chemical shifts will be important for accurate distance measurements.

To investigate the dependence of ${ }^{19} \mathrm{~F}$ spin exchange on internuclear distances, ${ }^{1} \mathrm{H}-{ }^{19} \mathrm{~F}$ dipolar couplings, and chemical shift differences, we studied four multi-fluorinated compounds, including PNC, sitagliptin, formyl-MLF, and 3F-Tyr-GB1 (Fig. 4-7). These compounds manifest a wide range of isotropic shift differences, from less than $1 \mathrm{ppm}$ between GB1 tyrosine resonances, to $80 \mathrm{ppm}$ between $\mathrm{CF}_{3}$ and aromatic fluorines in sitagliptin and formyl-MLF. Table 1 and Fig. S2 summarize the ${ }^{19} \mathrm{~F}$ chemical shift tensors in these compounds ${ }^{62}$. Peak assignment was based on well-known chemical shift trends, the measured spin exchange time constants, and the intramolecular distances from the crystal structures. SIMPSON simulations (not shown) confirm that ${ }^{19} \mathrm{~F}$ spin diffusion experiences rotor-driven polarization transfer with respect to the isotropic chemical shift difference ${ }^{61}$, which will not be discussed here. Instead, an MAS frequency of $25 \mathrm{kHz}$ was kept constant in the following experiments, which avoids rotational resonance between peaks.

PNC contains three aromatic fluorines separated by $4.7-9.4 \AA$ and have small ${ }^{19} \mathrm{~F}$ isotropic shift differences of $5.8-14.6$ ppm (Fig. 4a, b, Table 1). Dilution by Trp caused a second set of chemical shifts, which are not analyzed here (Fig. 4c). ${ }^{2}{ }^{19} \mathrm{~F}-{ }^{19} \mathrm{~F}$ CORD spectra revealed spin exchange buildup constants of $16 \mathrm{~ms}$ to $68 \mathrm{~ms}$ (Fig. 4d). Most buildup curves plateau to 0.33 , indicating equilibration of the magnetization among the three fluorines 
without considerable dipolar truncation affecting the plateau value ${ }^{17}$. Fig. $4 \mathrm{e}$ summarizes the buildup time constants, $t_{S D}=1 / k_{S D}$, for the three-spin system. Shorter time constants are found for shorter distances as expected. Asymmetric time constants (16.6 ms and $31.2 \mathrm{~ms}$ ) are observed between $\mathrm{F}_{\mathrm{P}}$ and $\mathrm{F}_{\mathrm{O}}$, which are separated by $4.7 \AA$, which may result from complex multi-spin effects with the third ${ }^{19} \mathrm{~F}$ or with the different proton environments of the two fluorines.

Sitagliptin is an example of a fluorinated pharmaceutical compound: it is an FDA-approved anti-diabetic compound containing a fluorinated $\beta$-amino acid linked to a trifluoromethylcontaining triazolopyrazine (Fig. 5a). The trifluorophenyl ring enhances binding to a hydrophobic pocket of the target protein while the $\mathrm{CF}_{3}$ group enhances activity by interacting electrostatically with the side chains of arginine and serine residues in the target protein ${ }^{34}$. Sitagliptin has large ${ }^{19} \mathrm{~F}$ isotropic chemical shift differences of up to $80 \mathrm{ppm}$ and inter- ${ }^{19} \mathrm{~F}$ distances up to $9.6 \AA$. The $1 \mathrm{D}{ }^{19} \mathrm{~F}$ spectrum resolves two sets of chemical shifts (Fig. 5b), with the narrower set corresponding to a mobile population of molecules, as shown by the absence of their signals in CP spectra (data not shown) and no associated cross-peaks in 2D correlation spectra (Fig. 5b). The spin exchange cross peaks of the rigid fraction of molecule show buildup time constants of 6.7 to $44.3 \mathrm{~ms}$ for distances of $4.7 \AA$ to $9.6 \AA$ (Fig. 5d). Asymmetric spin exchange rates are again observed, for example between $\mathrm{F}_{\mathrm{M}}$ and $\mathrm{F}_{\mathrm{O}}$, with time constant of $44.3 \mathrm{~ms}$ and $18.5 \mathrm{~ms}$. Here, we can attribute the slower

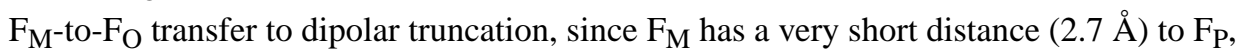
while the $\mathrm{F}_{\mathrm{O}}-\mathrm{F}_{\mathrm{P}}$ distance $(4.7 \AA)$ is considerably longer. Surprisingly, the $\mathrm{CF}_{3}$ group, which is 5.3 to $9.6 \AA$ away from the three aromatic fluorines, exhibits fast polarization transfer with time constants of 10 to $19 \mathrm{~ms}$. The internuclear distances for the trifluoromethyl group were calculated as the average of the three individual distances, thus the three ${ }^{19} \mathrm{~F}$ spins are represented by a pseudo-spin located at the center of the three ${ }^{19} \mathrm{~F}$ spins. Accounting for each of the trifluoromethyl spins separately, and considering that spin exchange rates scale with $r^{-6}$, the average internuclear distance is

$$
|r|=\left(\left(\sum_{i=1}^{3} r^{-6}\right) / 3\right)^{-1 / 6} .
$$

The resulting distances are close to those representing the trifluoromethyl group by a pseudo-spin, thus making the conclusions independent of the model used. In the pseudo-spin model, dipolar couplings with the trifluoromethyl group are simplified to a two-spin system experiencing an increased effective coupling strength.

To better understand the spin exchange trends between $\mathrm{CF}_{3}$ and aromatic fluorines, we also measured ${ }^{19} \mathrm{~F}^{19} \mathrm{~F}$ spin exchange in the tripeptide formyl-MLF (Fig. 6). Compared to sitagliptin, the $\mathrm{CF}_{3}$ distance to ${ }^{4-}{ }^{19} \mathrm{~F}-\mathrm{Phe}$ is relatively long, at $8.9 \AA$. A time constant of 345 $\mathrm{ms}$ is observed from $\mathrm{CF}_{3}$ to $\mathrm{F}_{\mathrm{P}}$, while the $\mathrm{F}_{\mathrm{P}}$-to- $\mathrm{CF}_{3}$ transfer is much faster, with a time constant of $65.6 \mathrm{~ms}$. This substantial asymmetry can be understood in terms of the effects of methyl rotation on intra-methyl ${ }^{19} \mathrm{~F}-{ }^{19} \mathrm{~F}$ dipolar coupling versus the $\mathrm{CF}_{3}-\mathrm{CF}$ dipolar coupling. For the long distance considered here, the trifluoromethyl rotation does not 
significantly affect the relative orientations of the three $\mathrm{F}_{\mathrm{P}}-\mathrm{CF}_{3}$ vectors, thus polarization transfer from $\mathrm{F}_{\mathrm{P}}$ to $\mathrm{CF}_{3}$ is largely unaffected by motion. At the same time, ${ }^{19} \mathrm{~F}-{ }^{19} \mathrm{~F}$ dipolar couplings among the three methyl fluorines are only reduced 2-fold from the rigid limit, giving a $5 \mathrm{kHz}$ averaged dipolar coupling. This coupling truncates the coupling with the remote $F_{p}$ spin, thus slowing down polarization transfer. Therefore, both the time constant and the plateau amplitude of spin exchange are highly directional in this spin system.

Fluorinated GB1 provides a realistic case of intramolecular ${ }^{19} \mathrm{~F}$ spin exchange in proteins, where multiple residues of the same type are incorporated. Fig. 7a shows the positions of the three Tyr residues in GB1 (PDB: 2LGI) ${ }^{63-64}$ Since the $3-{ }^{19} \mathrm{~F}$ and $5-{ }^{19} \mathrm{~F}$ positions are statistically equally present, there are eight isotopomers of Tyr-fluorinated GB1. However, since the distances involved are long, from $9 \AA$ to $16 \AA$, the distance variation due to the 3 and 5- mixing does not significantly alter the distance distribution. Therefore, we use the coupling-weighted average of the $3 \mathrm{~F}$ and 5F distances (Eq. (5)) in our analysis. Fig. 7b, c show that $\mathrm{Y} 3$ and $\mathrm{Y} 45$ isotropic chemical shifts are significantly overlapped $(0.4 \mathrm{ppm}$ difference), while Y33 is resolved by $2-3 \mathrm{ppm}$ from the other two peaks (Table 1). We thus analyzed the spin exchange rates between $\mathrm{Y} 3$ and $\mathrm{Y} 45$ by spectral deconvolution to reproduce the shape and position of the peak (Fig. 7d). Y3-Y45 polarization transfer across a distance of $5.3 \AA$ occur with time constants of 37 and $81 \mathrm{~ms}$, and is manifested as neardiagonal intensities between the two closely spaced peaks. In comparison, the Y45 and Y3 transfer to the resolved Y33 exhibit time constants of $174 \mathrm{~ms}$ and $530 \mathrm{~ms}$, corresponding to distances of 15.6 and $16.0 \AA$.

The $2 \mathrm{D}{ }^{19} \mathrm{~F}-{ }^{19} \mathrm{~F}$ exchange spectra in Fig. $4-7$ were measured under $25 \mathrm{kHz}$ MAS using the CORD mixing scheme, with a maximum mixing time of $300 \mathrm{~ms}$. When no ${ }^{1} \mathrm{H}$ irradiation was applied, the exchange rates slowed down more than 10-fold (Fig. 5e, Fig. S3). For sitagliptin, mixing times as long as $1.8 \mathrm{~s}$ were still insufficient for PDSD to reach equilibrium, and experiments with longer mixing times suffer from considerable $T_{1}$ relaxation. Even when the intensities are normalized to the integrated intensity of diagonal and cross peaks to compensate for the overall signal loss, several peaks show relaxation effects due to the large spread of relaxation times between the $\mathrm{CF}_{3}$ and aromatic fluorines. For spin diffusion rates that are not significantly faster than $T_{1}$ relaxation, $T_{1}$ relaxation interfere with spin diffusion by causing local magnetization gradients, leading to altered relaxation characteristics ${ }^{65-66}$ and biases to the cross-peak buildup curves. Therefore, CORD irradiation has significant benefit over PDSD for spectrally resolved ${ }^{19} \mathrm{~F}$ spin exchange, in contrast to the dependence of CODEX anisotropy spin exchange among spins with the same isotropic shift.

\section{Master curve for distance-dependent ${ }^{19} \mathrm{~F}$ spin exchange rates}

Given the large ranges of inter-fluorine distances and ${ }^{19} \mathrm{~F}$ chemical shifts in these model compounds, we asked whether a quantitative relationship exists between spin diffusion rates and distances. For spin pairs for which phenyl ring reorientation introduces multiple distances, mean distances were calculated by the $r^{-6}$-weighted average according to Eq. (5). We note that phenyl ring reorientation are much faster than the characteristic spin polarization exchange times, giving a single, average distance for each spin pair. While PNC 
and sitagliptin structures already include the fluorinated sites, F-F distances in formyl-MLF and GB1 were determined from their non-fluorinated analogues. Given the large F-F distances in these compounds, minor structural distortions due to fluorination are considered negligible. A simple plot of $k_{\mathrm{SD}}$ values with distances did not reveal a clear correlation with internuclear distances (Fig. 8, inset), which is not surprising since the ${ }^{19} \mathrm{~F}$ chemical shifts exert a strong influence on the spin exchange rates. We note that for ${ }^{1} \mathrm{H}$ spin diffusion under $100 \mathrm{kHz}$ MAS, where ${ }^{1} \mathrm{H}$ resonances become narrow enough to avoid resonance overlap, similar bias effects were obtained: cross-peak intensities after a fixed ${ }^{1} \mathrm{H}$ spin diffusion period without dipolar recoupling correlate with the chemical-shift offset between the ${ }^{1} \mathrm{H}$ resonances ${ }^{67}$. This situation stresses the strong effects of chemical-shift bias even for systems in which isotropic chemical-shift differences are small, provided that (residual) dipolar couplings are smaller than the chemical-shift offsets.

Since the spin diffusion rate is proportional to the overlap integral (Eq. (2)), which is inversely proportional to the square of the isotropic shift difference (Supporting Information), we next scaled the $k_{\mathrm{SD}}$ values by the squared isotropic shift difference within each spin pair. This treatment is equivalent to approximating the overlap integral as

$$
F(0) \approx f_{0} / \Delta \delta_{\text {iso }}^{2}
$$

where $f_{0}$ is a phenomenological constant. With this approximation, the spin diffusion rate can be expressed as

$$
k_{\mathrm{SD}} \Delta \delta_{\text {iso }}^{2}=0.5 \pi f_{0} \omega^{2}=\frac{c}{r^{6}}
$$

where the constant $c$ depends on $f_{0}$, the ${ }^{19} \mathrm{~F}$ gyromagnetic ratio, and the (powder averaged) orientation between the internuclear vector and the magnetic field. On a logarithmic scale, this chemical-shift modified rate then scales with distance $r$ as

$$
\log \left(k_{\mathrm{SD}} \Delta \delta_{\text {iso }}^{2}\right)=\log c-6 \log r
$$

Fig. 8 shows a logarithmic plot of $k_{S D} \Delta \delta_{\text {iso }}^{2}$ with respect to the distance $r$. Most data points fall onto two straight lines with the predicted slope of -6 , indicating data consistency and accuracy. Interestingly, the data points for the lower line correspond to $\mathrm{CF}-\mathrm{CF}$ spin exchange while the data points for the upper line represent $\mathrm{CF}_{3}-\mathrm{CF}$ exchange. The calibration constant for the CF-CF exchange curve corresponds to $c=1.0 \cdot 10^{14} \AA^{6} / \mathrm{s}^{3}$, while for $\mathrm{CF}_{3}-\mathrm{CF}$ exchange, the data indicate a 100 -fold larger $c$ of $1.5 \cdot 10^{16} \AA^{6} / \mathrm{s}^{3}$. Evidently, methyl rotational averaging of the ${ }^{19} \mathrm{~F} \mathrm{CSA}$ and simultaneous polarization transfer of three fluorines to a remote fluorine (or vice versa) significantly speeds up spin diffusion. 
The approximation used here to compensate for chemical-shift bias, Eq. (7), does not apply to overlapped peaks or to spin pairs in the strong-coupling limit (see Supporting Information). Thus, two outliers are expected and indeed observed using this approach. The partially overlapped Y3 and Y45 resonances in GB1 exhibit much slower spin diffusion rates than predicted by Eq. (7), which is fully consistent with the behavior of anisotropy spin exchange under ${ }^{1} \mathrm{H}$ irradiation. In the limit of negligible isotropic shift differences (strong coupling limit), ${ }^{19} \mathrm{~F}$ spin exchange is significantly impeded by DARR or CORD ${ }^{1} \mathrm{H}-{ }^{19} \mathrm{~F}$ dipolar recoupling. The second outlier belongs to the $2.7 \AA \mathrm{F}_{\mathrm{M}}-\mathrm{F}_{\mathrm{P}}$ distance in sitagliptin, whose associated ${ }^{19} \mathrm{~F}-{ }^{19} \mathrm{~F}$ dipolar coupling strength $(2 \pi \cdot 5.4 \mathrm{kHz})$ is comparable to the isotropic shift difference of $2 \pi \cdot 5.25 \mathrm{kHz}$. Therefore, this two-spin system also exists in the strong coupling limit, for which CORD recoupling impedes spin diffusion in a similar manner as observed for $5 \mathrm{~F}-\mathrm{Trp}$. Using $F_{\text {eff }}(0)=2 \mu$ s under $25 \mathrm{kHz}$ MAS and DARR irradiation (Table 2), and replacing the square of the angular dependence of dipolar couplings by its isotropic average of 0.2 , the internuclear distance is calculated to be $2.4 \AA$, which matches the expected internuclear distance well. Therefore, the master curves apply to spin systems only in the weak-coupling limit, where the ${ }^{19} \mathrm{~F}$ chemical shift differences exceed the ${ }^{19} \mathrm{~F}-{ }^{19} \mathrm{~F}$ dipolar couplings. This is the limit where we expect to find most applications of ${ }^{19} \mathrm{~F}$ NMR for structure determination, particularly when measuring long distances.

These two master curves are obtained from compounds with ${ }^{19} \mathrm{~F}-{ }^{19} \mathrm{~F}$ distances of $4.5-16 \AA$ and ${ }^{19} \mathrm{~F}$ isotropic chemical shifts of $-39 \mathrm{ppm}$ to $-138 \mathrm{ppm}$, reflecting a broad range of chemical structures. Therefore, the observation that the chemical-shift corrected spin exchange rates not only exhibit a rigorous dependence on $1 / r^{6}$ but also converge to a precise constant $c$, means that spin exchange rates can be used to determine inter-fluorine distances reliably. The ability to measure distances up to $1.6 \mathrm{~nm}$ without exogenous paramagnetic or fluorescent tags should significantly facilitate biomolecular structure determination. We note that the longest distance examined in this study was measured under considerable dipolar truncation, which causes low cross peak intensities. In the absence of dipolar truncation, distances up to $\sim 2 \mathrm{~nm}$ may be measurable. The asymmetry in polarization transfer does not compromise distance extraction, since the faster spin exchange rate within a pair of fluorines represents the more accurate distance.

\section{Conclusions}

The above ${ }^{19} \mathrm{~F}$ spin exchange data provide the first extensive and quantitative measurement of ${ }^{19} \mathrm{~F}-{ }^{19} \mathrm{~F}$ distances at a relatively high magnetic field of 14.1 Tesla under fast MAS, and take into account ${ }^{19} \mathrm{~F}$ chemical-shift bias. Even with the simple spin diffusion mechanism, distances up to $1.6 \mathrm{~nm}$ were measured within a mixing time of $300 \mathrm{~ms}$, making ${ }^{19} \mathrm{~F}$ spin exchange NMR a robust method for obtaining long-range distance constraints. For distances of $6-8 \AA,{ }^{19} \mathrm{~F}-{ }^{19} \mathrm{~F}$ spin exchange time constants of $10-35 \mathrm{~ms}$ were found, which are two orders of magnitude faster than ${ }^{13} \mathrm{C}-{ }^{13} \mathrm{C}$ spin exchange. ${ }^{19} \mathrm{~F}$ spin exchange is efficient both between spins with the same isotropic chemical shift and between spins with different isotropic shifts. For the former case, anisotropy spin exchange is the most efficient under 15 - $25 \mathrm{kHz}$ MAS, without ${ }^{1} \mathrm{H}$ irradiation, while DARR is detrimental. At even higher magnetic fields, the larger ${ }^{19} \mathrm{~F}$ CSA will further increase the MAS frequency regime for efficient spin 
exchange. In contrast, spectrally resolved ${ }^{19} \mathrm{~F}$ spin diffusion is facilitated by ${ }^{1} \mathrm{H}-{ }^{19} \mathrm{~F}$ dipolar recoupling. We discovered two master curves for $\mathrm{CF}-\mathrm{CF}$ and $\mathrm{CF}-\mathrm{CF}_{3}$ spin exchange, which relate the measured exchange rates with distances after taking into account isotropic chemical-shift differences. Therefore, ${ }^{19} \mathrm{~F}$ spin exchange NMR is a simple and robust approach for accurate distance measurements of ${ }^{19} \mathrm{~F}-{ }^{19} \mathrm{~F}$ distances in a wide range of molecular systems with high sensitivity.

\section{Supplementary Material}

Refer to Web version on PubMed Central for supplementary material.

\section{Acknowledgement:}

This work is supported by NIH grant GM066976 to M. H. and by a Leopoldina postdoctoral fellowship (grant number LPDS-2017-14) from the German National Academy of Science to M. R. The authors thank Mikaila Hoffmann for help with the analysis of the spin exchange data.

\section{References}

1. Hong M; Schmidt-Rohr K, Magic-Angle-Spinning NMR techniques for measuring long-range distances in biological macromolecules. Acc. Chem. Res 2013, 46, 2154-2163. [PubMed: 23387532]

2. Paëpe GD, Dipolar recoupling in magic angle spinning solid-state nuclear magnetic resonance. Annu. Rev. Phys. Chem 2012, 63, 661-684. [PubMed: 22404583]

3. Saalwächter K, Robust NMR approaches for the determination of homonuclear dipole-dipole coupling constants in studies of solid materials and biomolecules. Chem. Phys. Chem 2013, 14, 3000-3014. [PubMed: 23754803]

4. Saalwächter K; Schnell I, REDOR-based heteronuclear dipolar correlation experiments in multi-spin systems: rotor-encoding, directing, and multiple distance and angle determination. Solid State Nucl. Magn. Reson 2002, 22, 154-187. [PubMed: 12469809]

5. Lange A; Seidel K; Verdier L; Luca S; Baldus M, Analysis of proton-proton transfer dynamics in rotating solids and their use for 3D structure determination. J. Am. Chem. Soc 2003, 125, 1264012648. [PubMed: 14531708]

6. Castellani F; vanRossum B; Diehl A; Schubert M; Rehbein K; Oschkinat H, Structure of a protein determined by solid-state magic-angle spinning NMR spectroscopy. Nature 2002, 420, 98-102. [PubMed: 12422222]

7. Wang T; Williams JK; Schmidt-Rohr K; Hong M, Relaxation-compensated difference spin diffusion NMR for detecting 13C-13C long-range correlations in proteins and polysaccharides. J. Biomol. NMR 2015, 61, 97-107. [PubMed: 25510834]

8. Szeverenyi NM; Sullivan MJ; Maciel GE, Observation of spin exchange by Two-Dimensional Fourier Transform 13C Cross Polarization-Magic-Angle Spinning. J. Magn. Reson 1982, 47, 462475 .

9. Takegoshi K; Nakamura S; Terao T, ${ }^{13} \mathrm{C}-{ }^{1} \mathrm{H}$ dipolar-assisted rotational resonance in magic-angle spinning NMR. Chem. Phys. Lett 2001, 344, 631-637.

10. Morcombe CR; Gaponenko V; Byrd RA; Zilm KW, Diluting abundant spins by isotope edited radio frequency field assisted diffusion. J. Am. Chem. Soc 2004, 126, 7196-7197. [PubMed: 15186155]

11. De Paëpe G; Lewandowski JR; Loquet A; Böckmann A; Griffin RG, Proton assisted recoupling and protein structure determination. J. Chem. Phys 2008, 129, 245101. [PubMed: 19123534]

12. Hu B; Lafon O; Trébosc J; Chen Q; Amoureux JP, Broad-band homo-nuclear correlations assisted by $1 \mathrm{H}$ irradiation for bio-molecules in very high magnetic field at fast and ultra-fast MAS frequencies. J. Magn. Reson 2011, 212, 320-329. [PubMed: 21873091] 
13. Shen M; Liu Q; Trébosc J; Lafon O; Masuda Y; Takegoshi K; Amoureux JP; Hu B; Chen Q, Exploring various modulation-sideband recoupling conditions of SHA+ sequence at fast MAS. Solid State Nucl. Magn. Reson 2013, 55-56, 42-47.

14. Weingarth M; Demco DE; Bodenhausen G; Tekely P, Improved magnetization transfer in solidstate NMR with fast magic angle spinning. Chem. Phys. Lett 2009, 469, 342-348.

15. Hou G; Yan S; Trébosc J; Amoureux J-P; Polenova T, Broadband homonuclear correlation spectroscopy driven by combined R2nn sequences under fast magic angle spinning for NMR structural analysis of organic and biological solids. J. Magn. Reson 2013, 232, 18-30. [PubMed: 23685715]

16. Hu B; Trébosc J; Lafon O; Chen Q; Masuda Y; Takegoshi Y; Amoureux J-P, Very-long-distance correlations in proteins revealed by solid-state NMR spectroscopy. Chem. Phys. Chem 2012, 13, 3585-3588. [PubMed: 22890906]

17. Bayro MJ; Huber M; Ramachandran R; Davenport TC; Meier BH; Ernst M; Griffin RG, Dipolar truncation effect in magic-angle spinning NMR recoupling experiments. J. Chem. Phys 2009, 130, 114506. [PubMed: 19317544]

18. Ni QZ; Daviso E; Can TV; Markhasin E; Jawla SK; Swager TM; Temkin RJ; Herzfeld J; Griffin RG, High Frequency Dynamic Nuclear Polarization. Acc. Chem. Res 2013, 46, 1933-1941. [PubMed: 23597038]

19. Gullion T; Schaefer J, Rotational echo double resonance NMR. J. Magn. Reson 1989, 81, 196-200.

20. Kristiansen PE; Carravetta M; van Beek JD; Lai WC; Levitt MH, Theory and applications of supercycled symmetry-based recoupling sequences in solid-state nuclear magnetic resonance. J. Chem. Phys 2006, 124, 234510. [PubMed: 16821932]

21. Solomon I, Relaxation processes in a system of two spins. Phys. Rev 1955, 99, 559-565.

22. Nadaud PS; Helmus JJ; Kall SL; Jaroniec CP, Paramagnetic ions enable tuning of nuclear relaxation rates and provide long-range structural restraints in solid-state NMR of proteins. J. Am. Chem. Soc 2009, 131, 8108-8120. [PubMed: 19445506]

23. Nadaud PS; Helmus JJ; Sengupta I; Jaroniec CP, Rapid Acquisition of Multidimensional SolidState NMR Spectra of Proteins Facilitated by Covalently Bound Paramagnetic Tags J. Am. Chem. Soc 2010, 132, 9561-9563. [PubMed: 20583834]

24. Buffy JJ; Hong T; Yamaguchi S; Waring A; Lehrer RI; Hong M, Solid-State NMR Investigation of the Depth of Insertion of Protegin-1 in Lipid Bilayers Using Paramagnetic Mn2+. Biophys. J 2003, 85, 2363-2373. [PubMed: 14507700]

25. Su Y; Hu F; Hong M, Paramagnetic Cu(II) for Probing Membrane Protein Structure and Function: Inhibition Mechanism of the Influenza M2 Proton Channel. J. Am. Chem. Soc 2012, 134, 86938702. [PubMed: 22519936]

26. Wang T; Chen Y; Tabuchi A; Cosgrove DJ; Hong M, The Target of $\beta$-Expansin EXPB1 in Maize Cell Walls from Binding and Solid-State NMR Studies. Plant Physiol. 2016, 172, 2107-2119. [PubMed: 27729469]

27. Pintacuda G; Giraud N; Pierattelli R; Böckmann A; Bertini I; Emsley L, Solid-state NMR spectroscopy of a paramagnetic protein: assignment and study of human dimeric oxidized CuIIZnII superoxide dismutase (SOD). Angew. Chem. Int. Ed. Engl 2007, 46, 1079-1082. [PubMed: 17191298]

28. Gregory DH; Gerig JT, Structural effects of fluorine substitution in proteins. J. Comput. Chem 1990, 12, 180-185.

29. Merkel L; Schauer M; Antranikian G; Budisa N, Parallel incorporation of different fluorinated amino acids: on the way to "teflon" proteins. ChemBioChem 2010, 11, 1205-1507.

30. Salwiczek M; Nyakatura EK; Gerling UIM; Ye S; Koksch B, Fluorinated amino acids: compatibility with native protein structures and effects on protein-protein interactions. Chem. Soc. Rev 2011, 41, 2135-2171. [PubMed: 22130572]

31. Matei E; Gronenborn AM, (19)F Paramagnetic Relaxation Enhancement: A Valuable Tool for Distance Measurements in Proteins. Angew. Chem. Int. Ed. Engl 2016, 55, 150-154. [PubMed: 26510989] 
32. Eddy MT; Didenko T; Stevens RC; Wüthrich K, $\beta 2$-Adrenergic Receptor Conformational Response to Fusion Protein in the Third Intracellular Loop. Structure 2016, 24, 2190-2197. [PubMed: 27839952]

33. Manglik A; Kim TH; Masureel M; Altenbach C; Yang Z; Hilger D; Lerch MT; Kobilka TS; Thian FS; Hubbell WL; Prosser RS; Kobilka BK, Structural Insights into the Dynamic Process of $\beta 2$ Adrenergic Receptor Signaling. Cell 2015, 161, 1101-1111. [PubMed: 25981665]

34. Wang J; Sánchez-Roselló M; Aceña JL; del Pozo C; Sorochinsky AE; Fustero S; Soloshonok VA; Liu $\mathrm{H}$, Fluorine in pharmaceutical industry: fluorine-containing drugs introduced to the market in the last decade (2001-2011). Chem. Rev 2014, 114, 2432-2506. [PubMed: 24299176]

35. deAzevedo ER; Bonagamba TJ; Hu W; Schmidt-Rohr K, Centerband-only detection of exchange: efficient analysis of dynamics in solids by NMR. J. Am. Chem. Soc 1999, 121, 8411-8412.

36. Buffy JJ; Waring AJ; Hong M, Determination of peptide oligomerization in lipid membranes with magic-angle spinning spin diffusion NMR. J. Am. Chem. Soc 2005, 127, 4477-4483. [PubMed: 15783230]

37. Luo W; Hong M, Determination of the Oligomeric Number and Intermolecular Distances of Membrane Protein Assemblies by Anisotropic1H-Driven Spin Diffusion NMR Spectroscopy. J. Am. Chem. Soc 2006, 128, 7242-7451. [PubMed: 16734478]

38. Luo W; Mani R; Hong M, Sidechain conformation and gating of the M2 transmembrane peptide proton channel of influenza A virus from solid-state NMR. J. Phys. Chem 2007, 111, 1082510832.

39. Williams JK; Zhang Y; Schmidt-Rohr K; Hong M, pH-Dependent Conformation, Dynamics, and Aromatic Interaction of the Gating Tryptophan Residue of the Influenza M2 Proton Channel from Solid-State NMR. Biophys. J 2013, 104, 1698-1708. [PubMed: 23601317]

40. Mandala VS; Liao SY; Kwon B; Hong M, Structural Basis for Asymmetric Conductance of the Influenza M2 Proton Channel Investigated by Solid-State NMR Spectroscopy. J. Mol. Biol 2017, 429, 2192-2210. [PubMed: 28535993]

41. Williams JK; Shcherbakov AA; Wang J; Hong M, Protonation equilibria and pore-opening structure of the dual-histidine influenza B virus M2 transmembrane proton channel from solidstate NMR. J. Biol. Chem 2017, 292, 17876-17884. [PubMed: 28893910]

42. Salnikov ES; Raya J; De Zotti M; Zaitseva E; Peggion C; Ballano G; Toniolo C; Raap J; Bechinger B, Alamethicin Supramolecular Organization in Lipid Membranes from 19F Solid-State NMR. Biophys. J 2016, 111, 2450-2459. [PubMed: 27926846]

43. Gilchrist J,ML; Monde K; Tomita Y; Iwashita T; Nakanishi K; McDermott AE, Measurement of interfluorine distances in solids. J. Magn. Reson 2001, 152, 1-6. [PubMed: 11531358]

44. Chen Q; Schmidt-Rohr K, F-19 and C-13 NMR signal assignment and analysis in a perfluorinated ionomer (Nafion) by two-dimensional solid-state NMR. Macromolecules 2004, 37, 5995-6003.

45. Martineau C; Legein C; Buzare J-Y; Fayoncd F, On the assignment of ${ }^{19} \mathrm{~F}$ MAS NMR spectra of fluoroaluminates using through-space spectral edition of ${ }^{19} \mathrm{~F}-{ }^{27} \mathrm{Al}$ and ${ }^{19} \mathrm{~F}-{ }^{19} \mathrm{~F}$ connectivities. Phys. Chem. Chem. Phys 2008, 11, 950-957. [PubMed: 19177213]

46. Wang Q; Hu B; Fayon F; Trébosc J; Legein C; Lafon O; Deng F; Amoureux J-P, Double-quantum ${ }^{19} \mathrm{~F}-{ }^{19} \mathrm{~F}$ dipolar recoupling at ultra-fast magic angle spinning NMR: application to the assignment of 19F NMR spectra of inorganic fluorides. Phys. Chem. Chem. Phys 2009, 11, 10391-10395. [PubMed: 19890524]

47. Wang Q; Hu B; Lafon O; Trébosc J; Deng F; Amoureux J-P, Homonuclear dipolar recoupling under ultra-fast magic-angle spinning: Probing ${ }^{19} \mathrm{~F}-{ }^{19} \mathrm{~F}$ proximities by solid-state NMR. J. Magn. Reson 2010, 2010, 113-128.

48. Langer B; Schnell I; Spiess HW; Grimmer AR, Temperature calibration under ultrafast MAS conditions. J. Magn. Reson 1999, 182-186. [PubMed: 10329244]

49. Hou G; Yan S; Trébosc J; Amoureux J-P; Polenova T, Broadband homonuclear correlation spectroscopy driven by combined R2nn sequences under fast magic angle spinning for NMR structural analysis of organic and biological solids. J. Magn. Reson 2013, 232, 18-30. [PubMed: 23685715]

J Phys Chem B. Author manuscript; available in PMC 2019 January 01. 
50. deAzevedo ER; Kennedy SB; Hong M, Determination of slow motions in extensively isotopically labeled proteins by magic-angle-spinning ${ }^{13} \mathrm{C}$-detected ${ }^{15} \mathrm{~N}$ exchange NMR. Chem. Phys. Lett 2000, 321, 43-48.

51. Veshtort M; Griffin RG, SPINEVOLUTION: a powerful tool for the simulation of solid and liquid state NMR experiments. J Magn Reson 2006, 178, 248-82. [PubMed: 16338152]

52. Bak M; Nielsen NC, REPULSION A Novel Approach to Efficient Powder Averaging in SolidState NMR. J. Magn. Reson 1997, 125, 132-139. [PubMed: 9245368]

53. Roos M; Micke P; Saalwächter K; Hempel G, Moderate MAS enhances local ${ }^{1} \mathrm{H}$ spin exchange and spin diffusion. J. Magn. Reson 2015, 260, 28-37. [PubMed: 26397218]

54. Bak M; Rasmussen JT; Nielsen NC, SIMPSON: A general simulation program for solid-state NMR spectroscopy. J. Magn. Reson 2000, 147, 296-330. [PubMed: 11097821]

55. Dürr HN; Grage SL; Witter R; Ulrich AS, Solid state ${ }^{19}$ F NMR parameters of fluorine-labeled amino acids. Part I: Aromatic substituents. J. Magn. Reson 2008, 191, 7-15. [PubMed: 18155936]

56. deAzevedo ER; Bonagamba TJ; Hu W; Schmidt-Rohr K, Principle of centerband-only detection of the exchange and extension to a four-time CODEX. J. Chem. Phys 2000, 112, 8988-9001.

57. Schmidt-Rohr K; Spiess HW, Multidimensional solid-state NMR and polymers. Academic Press Inc: London, 1994.

58. Oas TG; Griffin RG; Levitt MH, Rotary resonance recoupling of dipolar interactions in solid-state nuclear magnetic resonance spectroscopy. J. Chem. Phys 1988, 89, 692-695.

59. Roos M; Micke P; Hempel G, Monitoring nuclear spin-flip processes and measuring spin-diffusion constants via hole burning into the magnetization. Chem. Phys. Lett 2012, 536, 147-154.

60. Chen Q; Schmidt-Rohr K, Measurement of the local ${ }^{1} \mathrm{H}$ spin-diffusion coefficient in polymers. Solid State Nucl. Magn. Reson 2006, 29, 142-152. [PubMed: 16263249]

61. Colombo MG; Meier BH; Ernst RR, Rotor-driven spin diffusion in natural-abundance ${ }^{13} \mathrm{C}$ spin systems. Chem. Phys. Lett 1988, 146, 189-196.

62. Eichele K HBA 1.7.5, Universität Tübingen, 2015.

63. Franks W; Wylie BJ; Frericks HL; Nieuwkoop AJ; Mayrhofer R; Shah GH; Graesser DT; Rienstra $\mathrm{CM}$, Dipole tensor-based refinement for atomic-resolution structure determination of a nanocrystalline protein by solid-state NMR spectroscopy. Proc. Natl. Acad. Sci. USA 2008, 105, 4621-4626. [PubMed: 18344321]

64. Wylie BJ; Sperling LJ; Nieuwkoop AJ; Franks WT; Oldfield E; Rienstra CM, Ultrahigh resolution protein structures using NMR chemical shift tensors. Proc. Nat. Acad. Sci. USA 2011, 108, 16974-16979. [PubMed: 21969532]

65. Kalk A; Berendsen HCJ, Proton magnetic relaxation and spin diffusion in proteins. J. Magn. Reson 1976, 24, 343-366.

66. Roos M; Hofmann M; Link S; Ott M; Balbach J; Rössler E; Saalwächter K; Krushelnitsky A, The "long tail" of the protein tumbling correlation function: observation by ${ }^{1} \mathrm{H}$ NMR relaxometry in a wide frequency and concentration range. J. Biomol. NMR 2015, 63, 403-415. [PubMed: 26582718]

67. Wittmann JJ; Agarwal V; Hellwagner J; Lends A; Cadalbert R; Meier BH; Ernst M, Accelerating proton spin diffusion in perdeuterated proteins at $100 \mathrm{kHz}$ MAS. J. Biomol. NMR 2016, 66, $233-$ 242. [PubMed: 27803998]

68. Takigawa T; Ashida T; Sasada Y; Kakudo M, The crystal structures of L-tryptophan hydrochloride and hydrobromide. Bull. Chem. Soc. Jpn 1966, 39, 2369-2378. [PubMed: 5978702]

69. Kaduk JA; Zhong K; Gindhart AM; Blanton TN, Crystal structure of sitagliptin dihydrogen phosphate monohydrate, $\mathrm{C}_{16} \mathrm{H}_{16} \mathrm{~F}_{6} \mathrm{~N}_{5} \mathrm{O}\left(\mathrm{H}_{2} \mathrm{PO}_{4}\right)\left(\mathrm{H}_{2} \mathrm{O}\right)$. Powder Diffr. 2016, 30, 349-356.

70. Rienstra CM; Tucker-Kellogg L; Jaroniec CP; Hohwy M; Reif B; McMahon MT; Tidor B; LozanoPerez T; Griffin RG, De novo determination of peptide structure with solid-state magic-angle spinning NMR spectroscopy. Proc. Natl. Acad. Sci. USA 2002, 99, 102060-10265. 
(a)

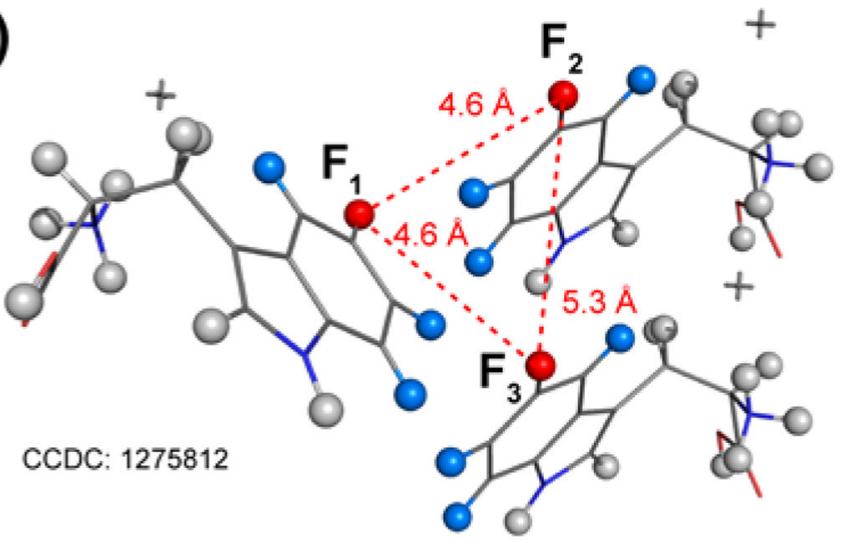

(b)

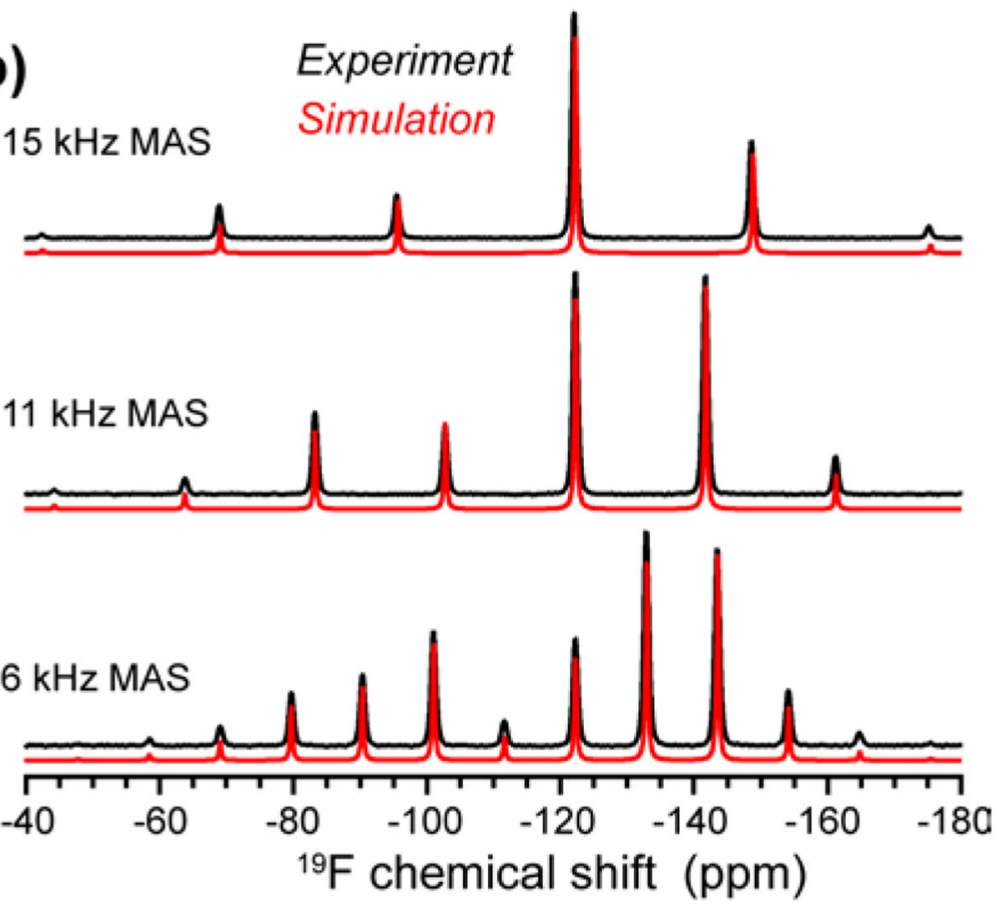

Figure 1.

Crystal structure and ${ }^{19} \mathrm{~F}$ spectrum of 5F-Trp. (a) Crystal structure of hydrogenated L-Trp ${ }^{68}$, where $\mathrm{H} 5$ has been replaced by ${ }^{19} \mathrm{~F}$ (red). The upper two molecules belong to the same unit cell. Hydrogen atoms that were included in the ${ }^{19} \mathrm{~F}$ spin exchange simulations are highlighted in blue. (b) Experimental (black) and simulated (red) ${ }^{19} \mathrm{~F}$ spectrum of $5 \mathrm{~F}-\mathrm{Trp}$ using SIMPSON and the parameters given in Table 1. 
(a) $25 \mathrm{kHz}$ MAS
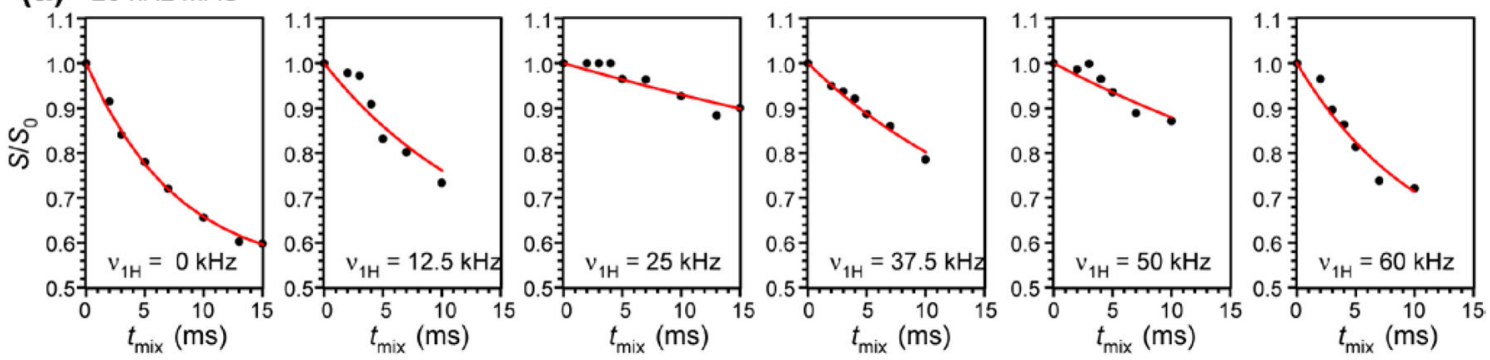

(b) $15 \mathrm{kHz}$ MAS
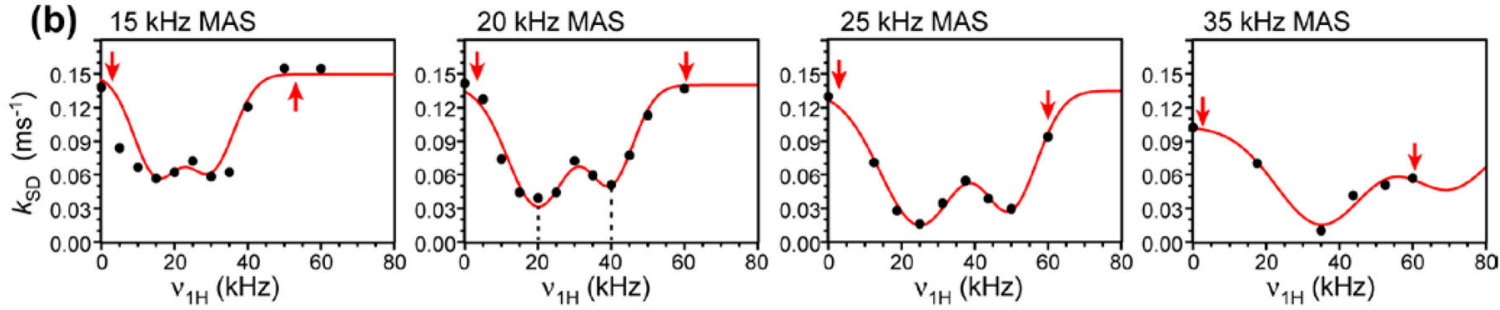

Figure 2.

${ }^{19} \mathrm{~F}$ CODEX spin exchange data of 5F-Trp. (a) CODEX decays (black) under $25 \mathrm{kHz}$ MAS for different ${ }^{1} \mathrm{H}$ irradiation field strengths. Best fits (red) used an equilibrium value of 0.53 \pm 0.03 , which was determined from the ${ }^{1} \mathrm{H}$-undecoupled spin diffusion data. (b) Spin exchange rates $k_{\mathrm{SD}}$ (points) as a function of the ${ }^{1} \mathrm{H}$ irradiation field strength, $\nu_{1 \mathrm{H}}$, for MAS frequencies of 15 to $35 \mathrm{kHz}$. Lines are sums of two Gaussian curves with fixed peak positions at $\nu_{1 \mathrm{H}}=\nu_{\mathrm{r}}$ and $\nu_{1 \mathrm{H}}=2 \nu_{\mathrm{r}}$. Arrows indicate lower- and upper-bound ${ }^{1} \mathrm{H}$ field strengths for which ${ }^{19} \mathrm{~F}$ spin diffusion is the fastest. 
(a)

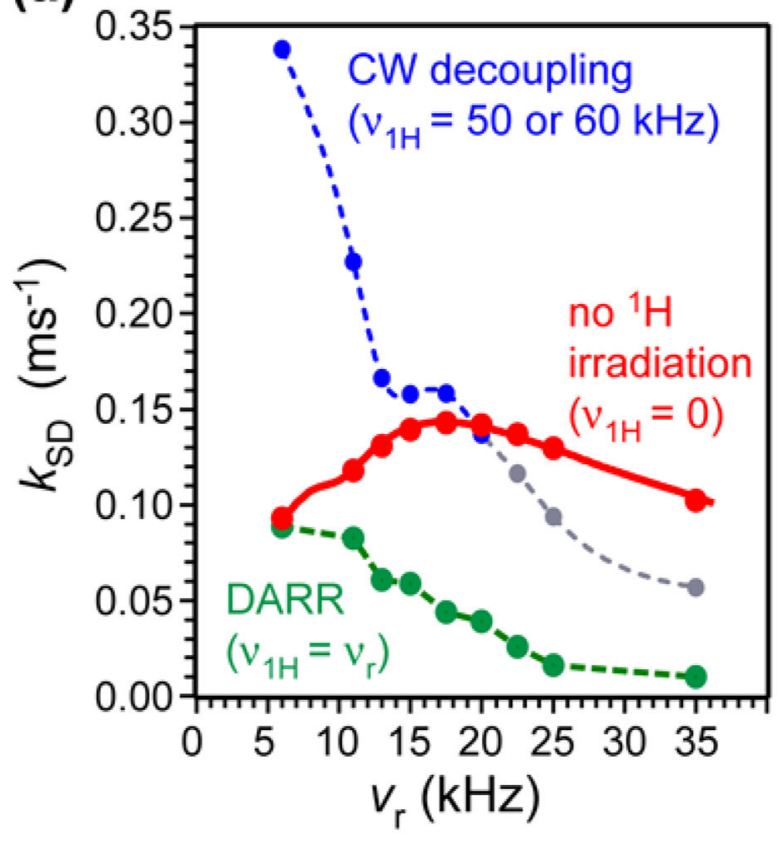

(b)
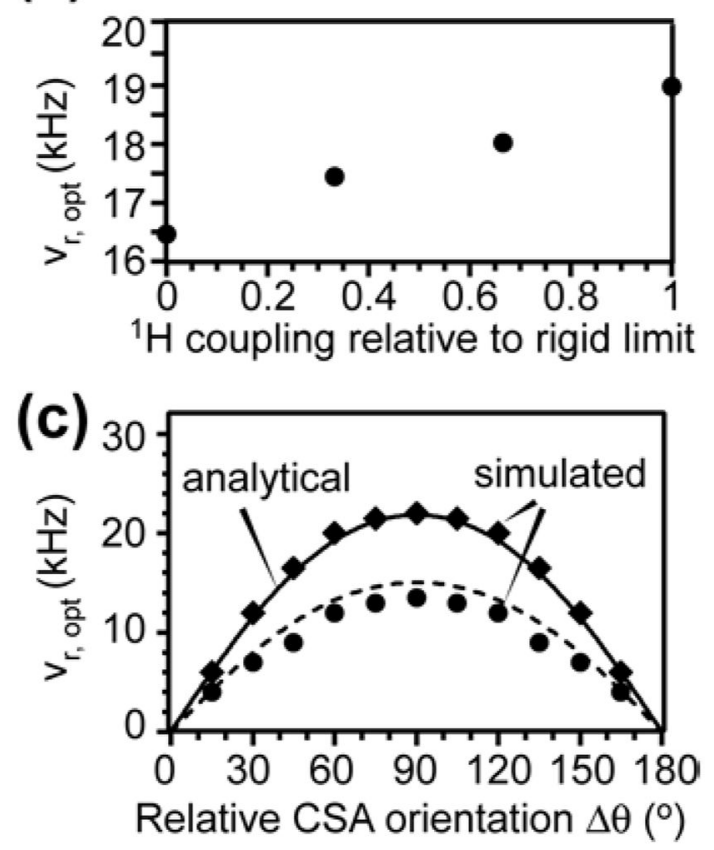

Figure 3.

Dependence of ${ }^{19} \mathrm{~F}$ spin exchange rates in 5F-Trp on the MAS frequency $\nu_{\mathrm{r}}$ at $564 \mathrm{MHz}$ Larmor frequency. (a) Measured (points) MAS dependence of spin exchange rates without ${ }^{1} \mathrm{H}$ irradiation $\left(\nu_{1 \mathrm{H}}=0\right)$, with DARR irradiation $\left(\nu_{1 \mathrm{H}}=v_{\mathrm{r}}\right)$, and with strong ${ }^{1} \mathrm{H}$ decoupling $\left(\nu_{1 \mathrm{H}} \geq 50 \mathrm{kHz}\right)$. For MAS frequencies larger than $20 \mathrm{kHz},{ }^{1} \mathrm{H} \mathrm{CW}$ decoupling interferes with the $n=2$ DARR condition and slows down ${ }^{19} \mathrm{~F}$ spin exchange (grey circles). Dashed lines are guides to the eye, while the solid line for the ${ }^{1} \mathrm{H}$-undecoupled data is from SPINEVOLUTION simulations using three ${ }^{19} \mathrm{~F}$ spins and nine nearest protons (Fig. 1a). (b) Optimal MAS frequency for ${ }^{1} \mathrm{H}$ undecoupled ${ }^{19} \mathrm{~F}$ spin exchange, obtained from SPINEVOLUTION simulation, for different ${ }^{1} \mathrm{H}-{ }^{1} \mathrm{H}$ and ${ }^{1} \mathrm{H}-{ }^{19} \mathrm{~F}$ dipolar couplings. (c) Numerical simulations (symbols) and analytical prediction (lines) of the optimal MAS frequency as a function of the angle $\Delta \theta$ between the two ${ }^{19} \mathrm{~F}$ chemical shift tensors. The upper curve corresponds to CSA parameters of $\Delta \delta=75 \mathrm{ppm}$ and $\eta=0.5$, while the lower curve corresponds to the 5F-Trp CSA parameters of $\Delta \delta=52 \mathrm{ppm}$ and $\eta=0.04$. 
(a)

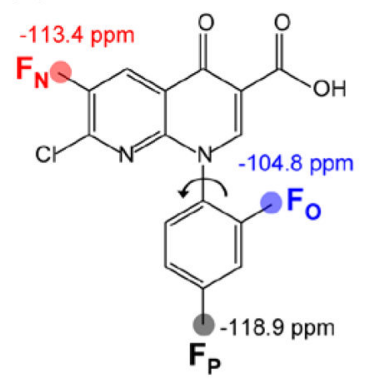

(d)

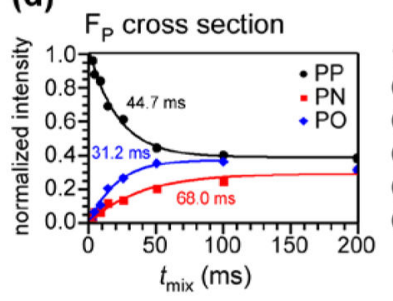

(b)
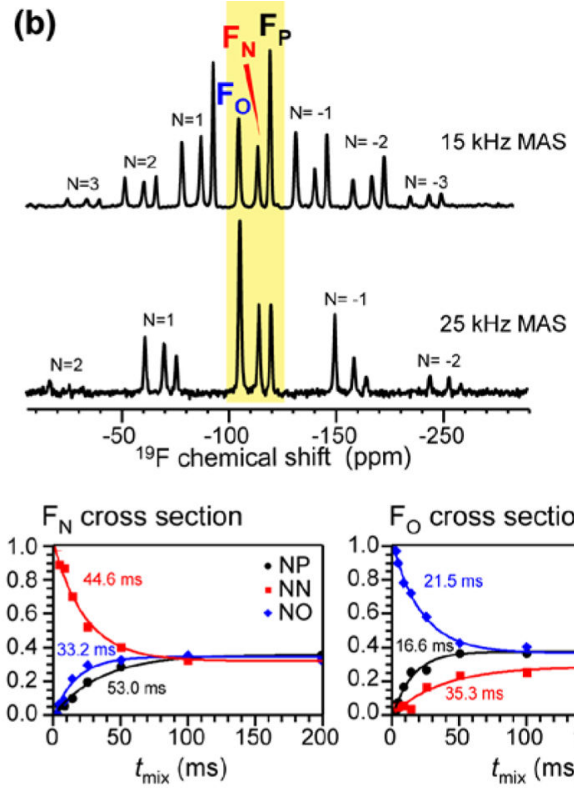

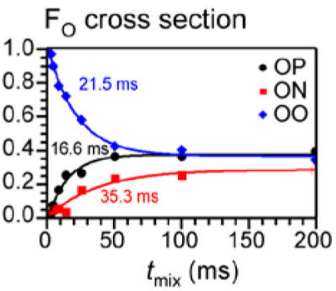

(c)

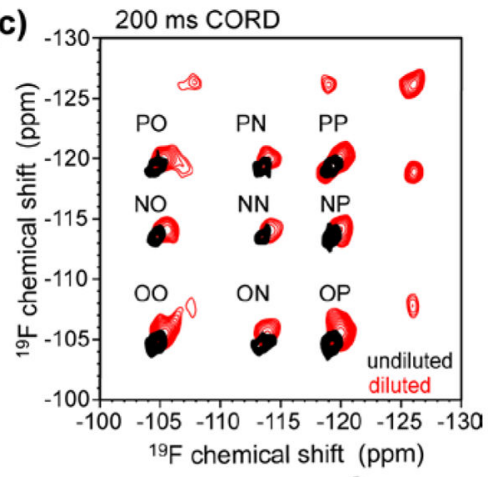

(e)

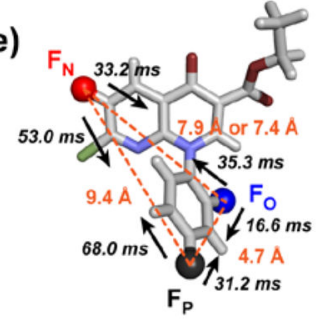

Figure 4.

${ }^{19} \mathrm{~F}$ spin exchange of PNC. (a) Chemical structure of PNC, indicating the isotropic chemical shifts of the three fluorines. (b) ${ }^{19} \mathrm{~F} \mathrm{CP}$ spectrum at $15 \mathrm{kHz}$ and $25 \mathrm{kHz}$ MAS. Centerband peaks $(N=0)$ are shaded in yellow. Significant sideband intensities $(N \neq 0)$ are seen at 15 kHz MAS. (c) 2D ${ }^{19} \mathrm{~F}-{ }^{19} \mathrm{~F}$ correlation spectrum measured using $200 \mathrm{~ms}$ CORD for undiluted (black) and $1: 5$ diluted (red) PNC. Additional peaks in the diluted spectrum result from perturbation by the diluting compound Trp, and are not analyzed. (d) Normalized intensities of cross peaks and diagonal peaks as a function of mixing time. Bestfit exponential time constants $t_{\mathrm{SD}}=1 / k_{\mathrm{SD}}$ are indicated. (e) Polarization exchange time constants for the ${ }^{19} \mathrm{~F}-{ }^{19} \mathrm{~F}$ distances in the molecular structure of PNC. 
(a)

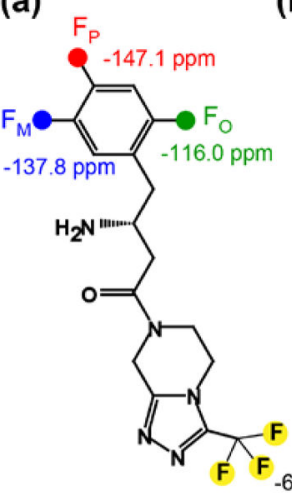

(b)

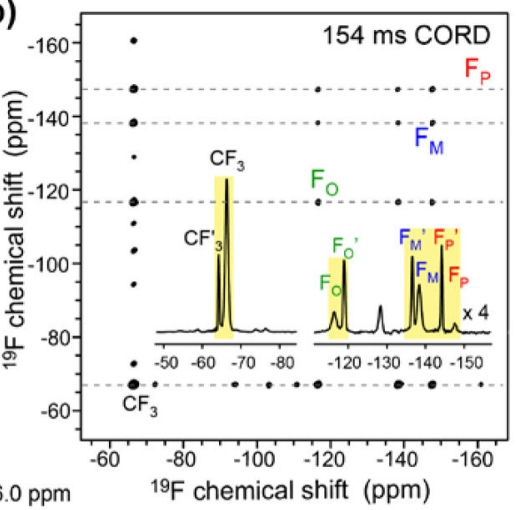

(d)

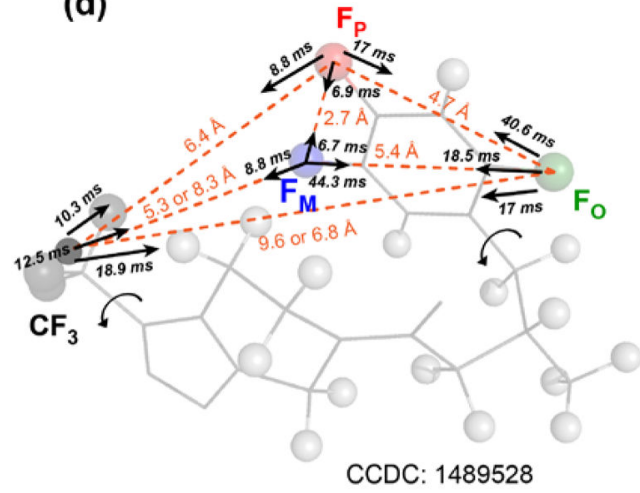

(c)
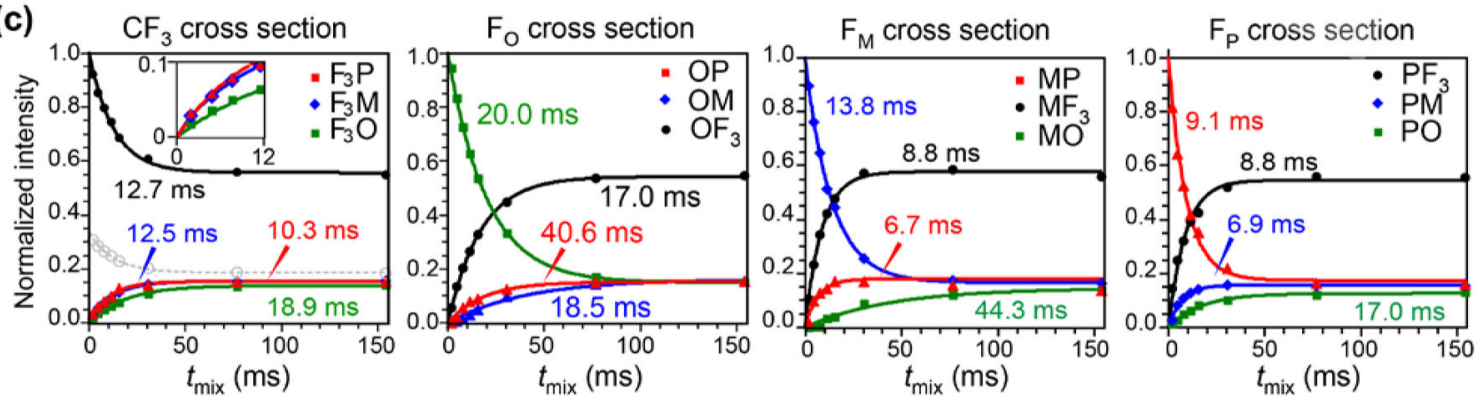

(e)
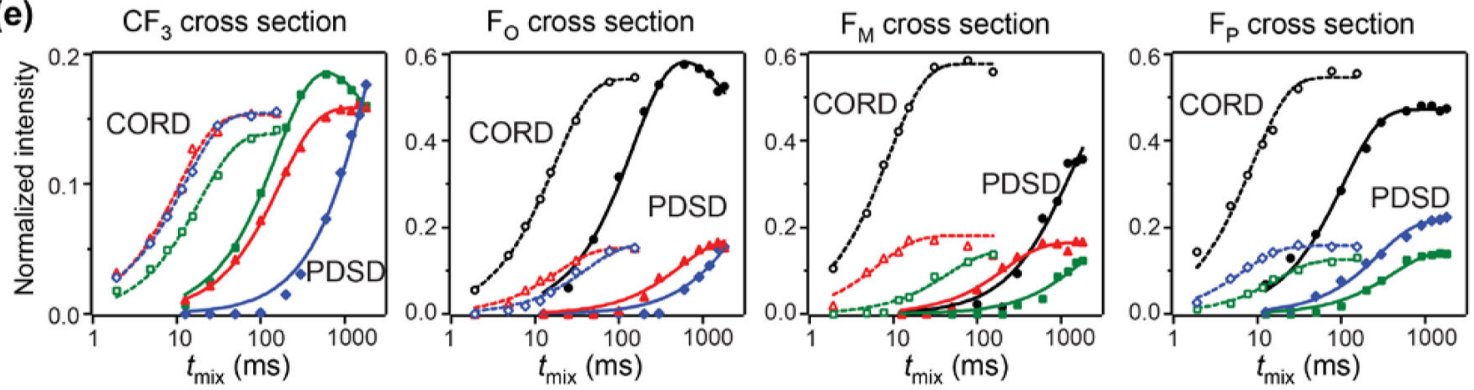

Figure 5.

${ }^{19} \mathrm{~F}$ spin exchange data of sitagliptin. (a) Chemical structure of sitagliptin and ${ }^{19} \mathrm{~F}$ isotropic chemical shifts. (b) $2 \mathrm{D}{ }^{19} \mathrm{~F}-{ }^{19} \mathrm{~F}$ correlation spectrum of diluted sitagliptin, measured under $25 \mathrm{kHz}$ MAS using $154 \mathrm{~ms}$ CORD mixing. Inset: ${ }^{19} \mathrm{~F}$ direct polarization spectrum at $35 \mathrm{kHz}$ MAS. Assignment for the set of ${ }^{19} \mathrm{~F}$ signals that show correlation peaks is given. (c) Normalized intensities of cross peaks and diagonal peaks as a function of CORD mixing time. (d) Best-fit spin exchange time constants for the ${ }^{19} \mathrm{~F}-{ }^{19} \mathrm{~F}$ distances in sitagliptin ${ }^{69}$. Protons are shown as gray spheres. (e) Comparison of CORD (open symbols) and PDSD (filled symbols) ${ }^{19} \mathrm{~F}$ spin exchange buildup curves plotted on a logarithmic time axis. CORD spin exchange is much faster than PDSD. Intensity drops at long PDSD mixing times result from $T_{1}$ relaxation. 


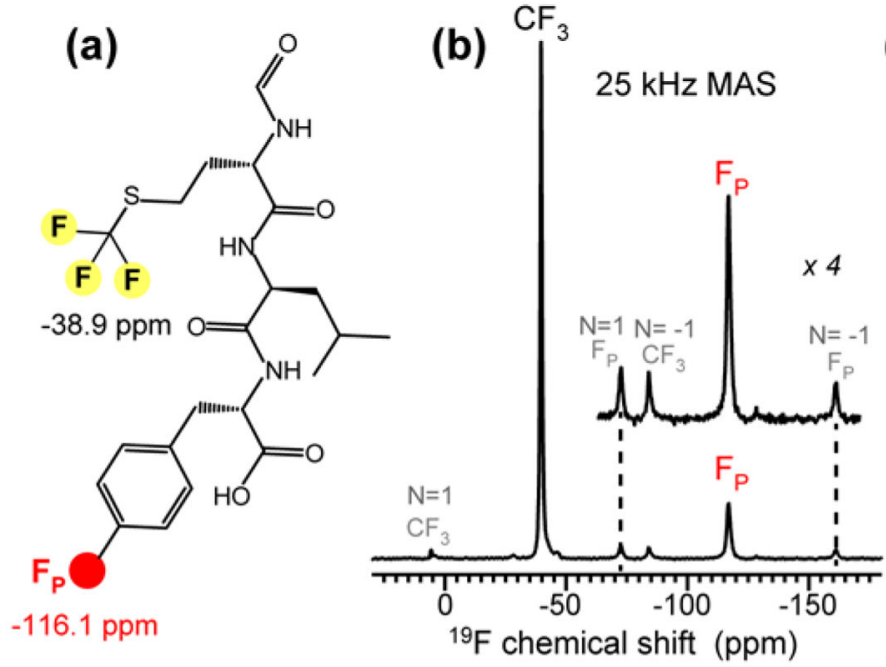

(d) $\mathrm{CF}_{3}$ cross section

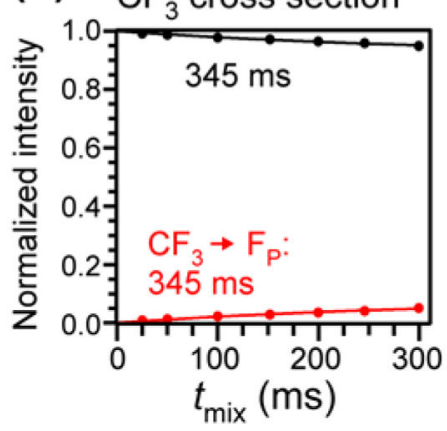

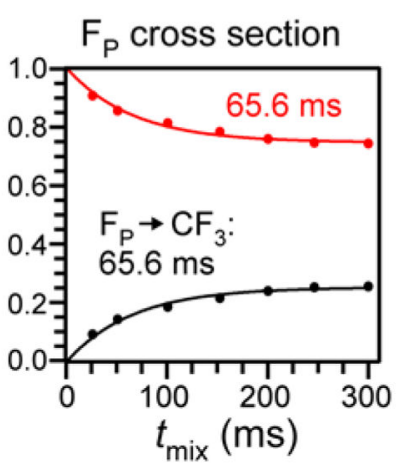

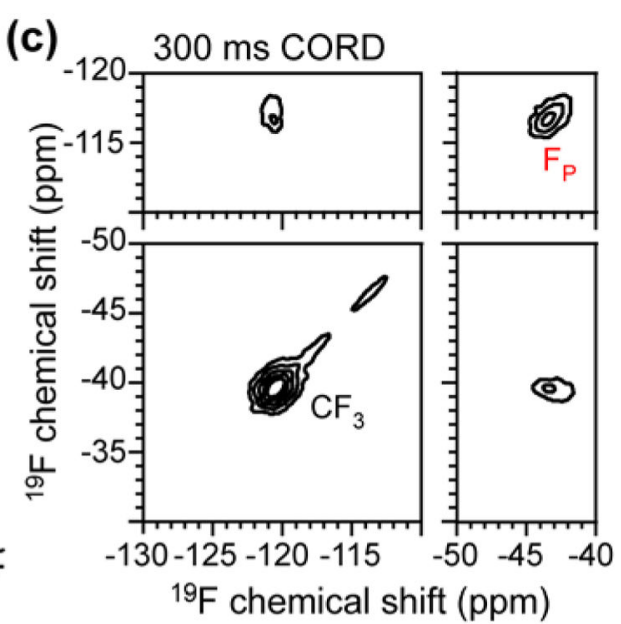

(e)

PDB: $1 \mathrm{q} 70$

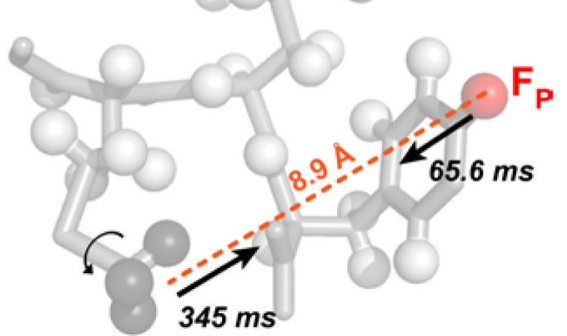

Figure 6.

${ }^{19} \mathrm{~F}$ spin exchange of formyl-MLF. (a) Chemical structure and ${ }^{19} \mathrm{~F}$ isotropic chemical shifts. (b) ${ }^{19} \mathrm{~F}$ DP spectrum (black) at $25 \mathrm{kHz}$ MAS. (c) $2 \mathrm{D}{ }^{19} \mathrm{~F}-{ }^{19} \mathrm{~F}$ correlation spectrum measured using $300 \mathrm{~ms}$ CORD mixing. (d) Normalized intensities of the cross peaks and diagonal peaks as a function of mixing time. (e) Spin exchange time constants for the ${ }^{19} \mathrm{~F}-{ }^{19} \mathrm{~F}$ distance in formyl-MLF (PDB: $1 \mathrm{q} 7 \mathrm{o}^{70}$ ). 
(a)

(b)

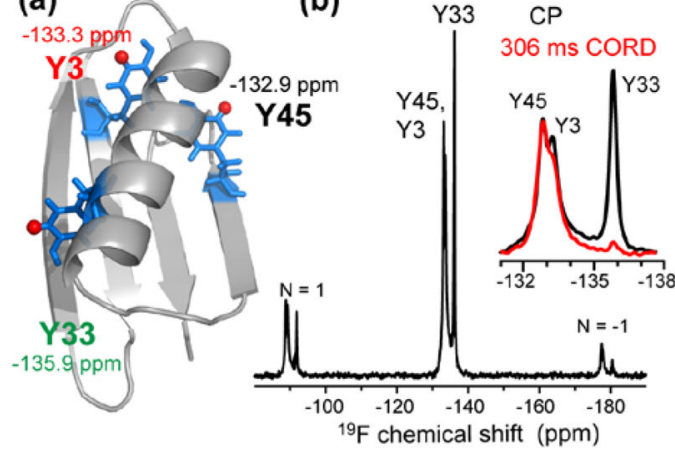

(e)
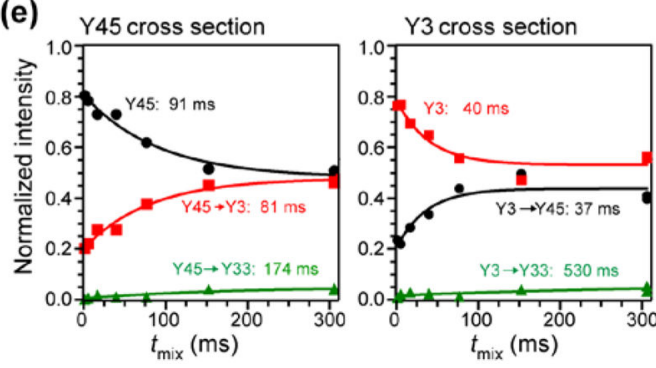

(c)

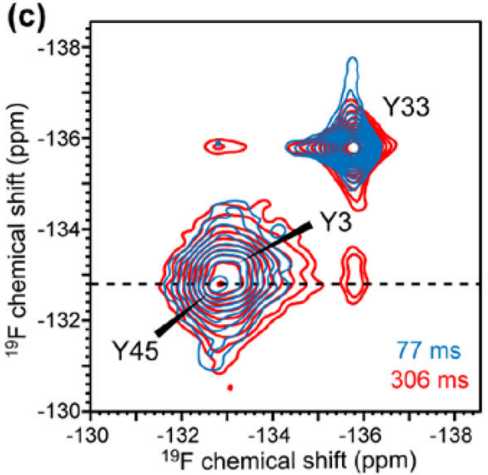

(d)

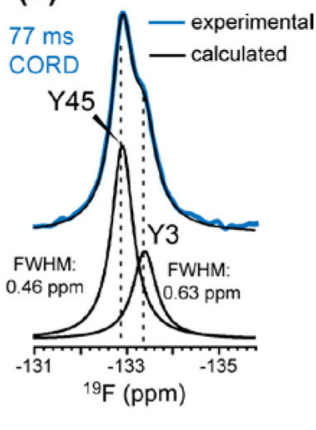

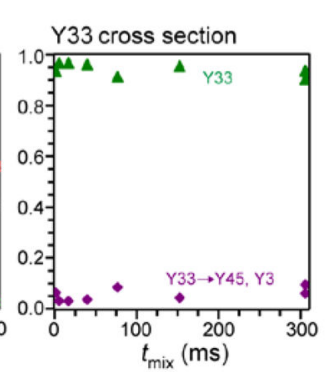

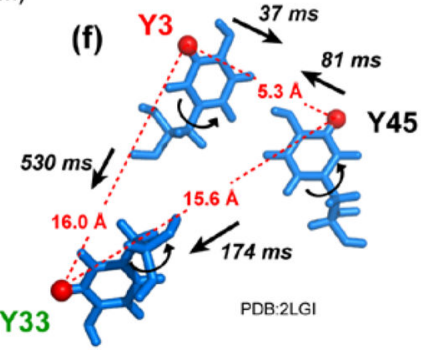

Figure 7.

${ }^{19} \mathrm{~F}$ spin exchange of 3F-Tyr-GB1. (a) GB1 structure (PDB: $2 \mathrm{JSV}^{63}$ ) and the ${ }^{19} \mathrm{~F}$ isotropic chemical shifts. (b) ${ }^{19} \mathrm{~F} \mathrm{CP}$ spectrum at $25 \mathrm{kHz}$ MAS. Inset: isotropic peaks from the ${ }^{19} \mathrm{~F} \mathrm{CP}$ spectrum (black) overlaid with the Y45 cross section ( $-132.9 \mathrm{ppm}$ ) of the $306 \mathrm{~ms}$ 2D CORD spectrum (red). (c) $2 \mathrm{D}{ }^{19} \mathrm{~F}-{ }^{19} \mathrm{~F}$ correlation spectra with $77 \mathrm{~ms}$ (blue) and $306 \mathrm{~ms}$ (red) mixing. (d) Peak deconvolution of Y45 and Y3. (e) Normalized intensities of cross peaks and diagonal peaks as a function of mixing time. (f) ${ }^{19} \mathrm{~F}$ spin exchange time constants of the three ${ }^{19} \mathrm{~F}$ sites for the ${ }^{19} \mathrm{~F}-{ }^{19} \mathrm{~F}$ distances in GB1. The distances are the average distances for $3-{ }^{19} \mathrm{~F}$ and $5-{ }^{19} \mathrm{~F}$ positions. 


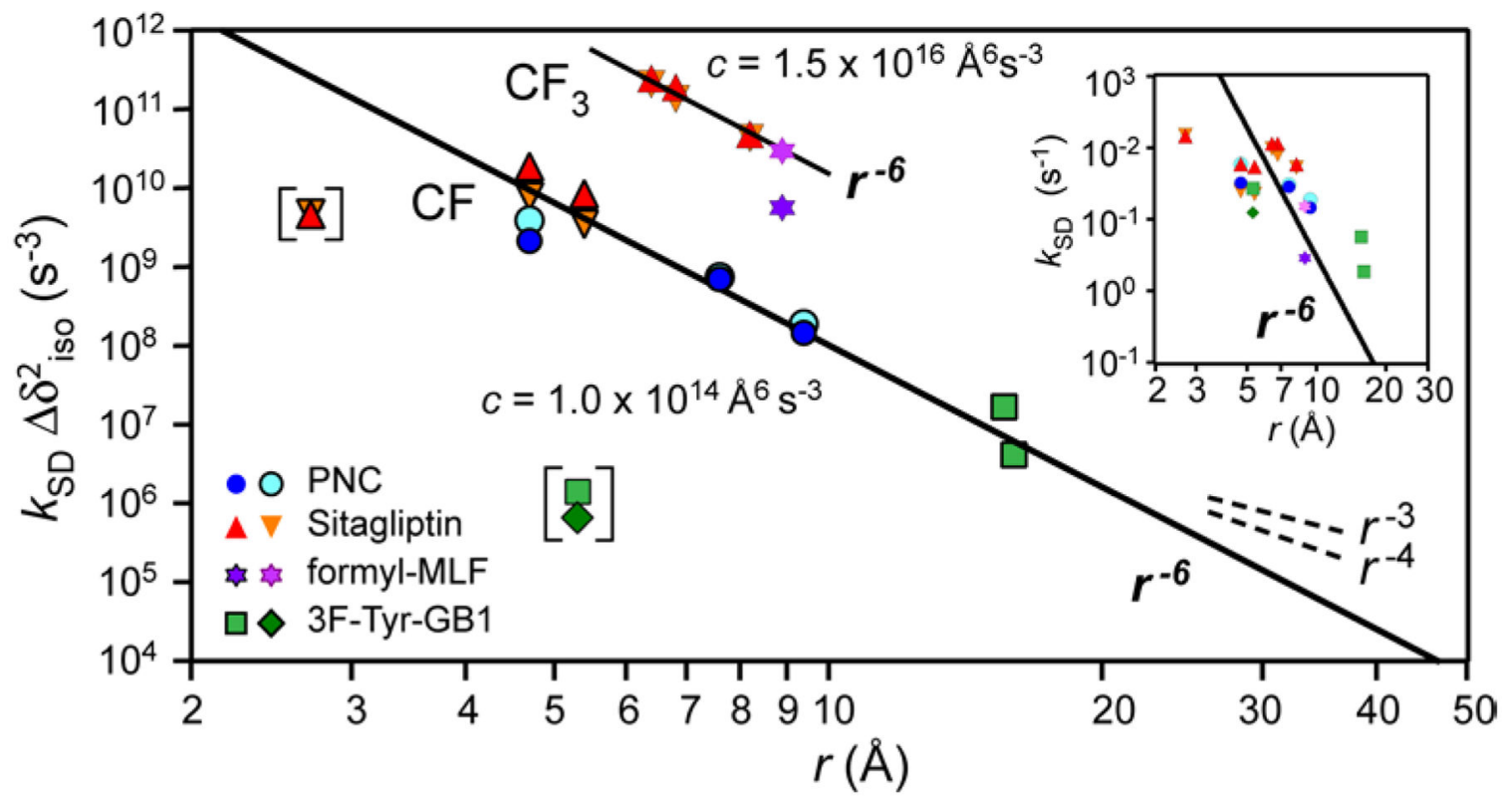

Figure 8.

Chemical-shift modified spin exchange rates as a function of ${ }^{19} \mathrm{~F}-{ }^{19} \mathrm{~F}$ distances. Two buildup rates are observed per spin pair. Solid lines have a slope of -6 to indicate the $1 / r^{6}$ dependence, cf. Eq. (7). CF-CF spin exchange has a distinct and smaller proportionality constant $c$ than $\mathrm{CF}-\mathrm{CF}_{3}$ spin exchange, but both show the $1 / r^{6}$ dependence. Data points in brackets are expected outliers, to which the chemical-shift correction does not apply; see main text and Supporting Information. 
Table 1.

${ }^{19} \mathrm{~F}$ chemical shift tensor parameters of the compounds studied in this work. Chemical shift anisotropies are obtained from Herzfeld-Berger analysis ${ }^{62}$.

\begin{tabular}{llllc}
\hline Compounds & Sites & $\delta_{\text {iso }}(\mathbf{p p m})$ & $\Delta \delta=\delta_{\text {zz }}-\delta_{\text {iso }}(\mathbf{p p m})$ & $\eta$ \\
\hline 5F-Trp & $5-{ }^{19} \mathrm{~F}$ & -122.1 & $53.7 \pm 0.8$ & $0.04 \pm 0.08$ \\
PNC & $\mathrm{F}_{\mathrm{N}}$ & -113.4 & $-89.1 \pm 2.2$ & $0.52 \pm 0.04$ \\
& $\mathrm{~F}_{\mathrm{P}}$ & -118.9 & $-75.9 \pm 0.9$ & $0.42 \pm 0.06$ \\
& $\mathrm{~F}_{\mathrm{O}}$ & -104.8 & $77.2 \pm 0.2$ & $0.80 \pm 0.06$ \\
Sitagliptin & $\mathrm{F}_{\mathrm{M}}$ & -137.8 & $-77.8 \pm 2.7$ & $0.51 \pm 0.01$ \\
& $\mathrm{~F}_{\mathrm{P}}$ & -147.1 & $-74.2 \pm 1.6$ & $0.47 \pm 0.04$ \\
& $\mathrm{~F}_{\mathrm{O}}$ & -116.0 & $-74.9 \pm 1.0$ & $0.78 \pm 0.01$ \\
& $\mathrm{CF}_{3}$ & -66.0 & $35.2 \pm 2.3$ & $0.03 \pm 0.04$ \\
Formyl-MLF & $\mathrm{F}_{\mathrm{P}}$ & -116.1 & $58.0 \pm 0.8$ & $0.94 \pm 0.02$ \\
& $\mathrm{CF}_{3}$ & -38.9 & $19.3 \pm 0.4$ & $0.85 \pm 0.03$ \\
GB1 & $3-{ }^{19} \mathrm{~F}-\mathrm{Y3}$ & -133.3 & $-76 \pm 3$ & $0.4 \pm 0.2$ \\
& $3-{ }^{19} \mathrm{~F}-\mathrm{Y} 33$ & -135.9 & $-56.2 \pm 0.7$ & $0.2 \pm 0.2$ \\
& $3-{ }^{19} \mathrm{~F}-\mathrm{Y} 45$ & -132.9 & $-75 \pm 1$ & $0.4 \pm 0.1$ \\
\hline
\end{tabular}

J Phys Chem B. Author manuscript; available in PMC 2019 January 01. 
Table 2.

Effective overlap integral $F_{\text {eff }}(0)$ for $5-{ }^{19} \mathrm{~F}-\operatorname{Trp}$ as a function of MAS frequency $v_{\mathrm{r}}$ and ${ }^{1} \mathrm{H}$ irradiation during the CODEX mixing time.

\begin{tabular}{llll}
\hline$v_{\mathbf{r}}(\mathbf{k H z})$ & \multicolumn{2}{c}{$\boldsymbol{F}_{\text {eff }}(\mathbf{0})(\boldsymbol{\mu s})$} \\
& PDSD & DARR & CW decoupling \\
\hline 6 & 14 & 13 & 50 \\
11 & 18 & 12 & 34 \\
13 & 19 & 9 & 25 \\
15 & 21 & 9 & 23 \\
17.5 & 21 & 7 & 23 \\
20 & 21 & 6 & 20 \\
22.5 & 20 & 4 & 17 \\
25 & 19 & 2 & 14 \\
35 & 15 & 2 & 8 \\
\hline
\end{tabular}

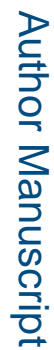

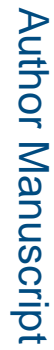

J Phys Chem B. Author manuscript; available in PMC 2019 January 01. 